\title{
The ubiquitin proteasome system in glia and its role in neurodegenerative diseases
}

\author{
Anne H. P. Jansen ${ }^{1}$, Eric A. J. Reits ${ }^{1}{ }^{*}$ and Elly M. Hol ${ }^{2,3,4}$ * \\ 1 Department of Cell Biology and Histology, Academic Medical Center, Amsterdam, Netherlands \\ ${ }^{2}$ Department of Translational Neuroscience, Brain Center Rudolf Magnus, University Medical Center Utrecht, Utrecht, Netherlands \\ ${ }^{3}$ Netherlands Institute for Neuroscience, Institute of the Royal Netherlands Academy of Arts and Sciences, Amsterdam, Netherlands \\ ${ }^{4}$ Swammerdam Institute for Life Sciences, Center for Neuroscience, University of Amsterdam, Netherlands
}

Edited by:

Fred van Leeuwen, Maastricht

University, Netherlands

\section{Reviewed by:}

Eldi Schonfeld-Dado, Stanford

University, USA

Inbal Goshen, The Hebrew University, Israel

\section{*Correspondence:}

Eric A. J. Reits, Department of Cell Biology and Histology, Academic Medical Center, Meibergdreef 9, 1105

AZ Amsterdam, Netherlands

e-mail: e.a.reits@amc.uva.nl;

Elly M. Hol, Department of

Translational Neuroscience, Brain

Center Rudolf Magnus, University

Medical Center Utrecht,

Universiteitsweg 100, Utrecht,

Netherlands

e-mail:e.m.hol-2@umcutrecht.nl
The ubiquitin proteasome system (UPS) is crucial for intracellular protein homeostasis and for degradation of aberrant and damaged proteins. The accumulation of ubiquitinated proteins is a hallmark of many neurodegenerative diseases, including amyotrophic lateral sclerosis, Alzheimer's, Parkinson's, and Huntington's disease, leading to the hypothesis that proteasomal impairment is contributing to these diseases. So far, most research related to the UPS in neurodegenerative diseases has been focused on neurons, while glial cells have been largely disregarded in this respect. However, glial cells are essential for proper neuronal function and adopt a reactive phenotype in neurodegenerative diseases, thereby contributing to an inflammatory response. This process is called reactive gliosis, which in turn affects UPS function in glial cells. In many neurodegenerative diseases, mostly neurons show accumulation and aggregation of ubiquitinated proteins, suggesting that glial cells may be better equipped to maintain proper protein homeostasis. During an inflammatory reaction, the immunoproteasome is induced in glia, which may contribute to a more efficient degradation of disease-related proteins. Here we review the role of the UPS in glial cells in various neurodegenerative diseases, and we discuss how studying glial cell function might provide essential information in unraveling mechanisms of neurodegenerative diseases.

Keywords: astrocytes, microglia, oligodendrocytes, gliosis, ubiquitin proteasome system, neurodegenerative diseases

\section{THE UBIQUITIN PROTEASOME SYSTEM}

Protein homeostasis is essential for proper function of a cell; therefore both protein synthesis and degradation are tightly regulated. Although there is a complex interplay between the two systems, in general, there are two main machineries involved in protein degradation: autophagy and the ubiquitin proteasome system (UPS). Autophagy involves lysosomal degradation by the formation of intracellular vesicles (autophagosomes) and is subdivided in chaperone-mediated autophagy (CMA), microautophagy, and macroautophagy. In CMA, chaperone proteins bind specifically to a KFERQ domain in a cytosolic protein, afterward it is internalized and degraded. Microautophagy is the direct lysosomal digestion of cytoplasmic content, which is trapped by random invagination of the lysosomal membrane. Macroautophagy functions as bulk degradation of mainly longlived proteins, protein aggregates and organelles, and involves autophagosome formation to isolate cytoplasmic proteins. The UPS selectively targets individual proteins, including short-lived, damaged or defectively folded proteins, which accounts for about $80-90 \%$ of all intracellular proteins (Rock etal., 1994; Lilienbaum, 2013).

The UPS consists of two key components: the ubiquitination system, which selects and targets proteins towards degradation by ubiquitinating them, and the proteasome, a multimeric protein complex that actually performs the degradation. Protein degradation is a tightly regulated process: before a protein is cleaved by the proteasome, an elaborate process of selection and targeting has taken place exerted by the ubiquitin (Ub) system. This system mediates the conjugation of Ub, a small 76-aminoacid-long modifier. Binding of Ub to the target protein takes place in a three-step reaction. First, Ub is linked to an Ub-activating enzyme (E1) in an ATP-dependent manner. Subsequently, the activated $\mathrm{Ub}$ is transferred to an E2 conjugating enzyme, followed by attachment of E2 to a specific E3 ubiquitin ligase enzyme that binds the target protein. Lastly, Ub is transferred by the E2 enzyme to the target protein (Figure 1). Ub itself can be ubiquitinated at one of its seven lysine residues, resulting in various polyubiquitin chain types that each has its own specific signal function. Regulation of protein degradation is also mediated by deubiquitinating enzymes (DUBs) that can reverse ubiquitination by removing Ub residues of mono- or polyubiquitinated proteins (Glickman and Ciechanover, 2002; Lilienbaum, 2013).

Polyubiquitinated proteins are generally degraded by the $26 \mathrm{~S}$ proteasome, which consists of a barrel-shaped 20S core that is the actual protease and a $19 \mathrm{~S}$ regulatory complex that recognizes and unfolds the ubiquitinated substrate (Figure 1). The $20 S$ core consists of two rings of seven $\alpha$ subunits, flanking two rings of seven $\beta$ subunits. Three of these seven $\beta$ subunits are catalytically active, with a caspase-like $(\beta 1)$, trypsin-like 


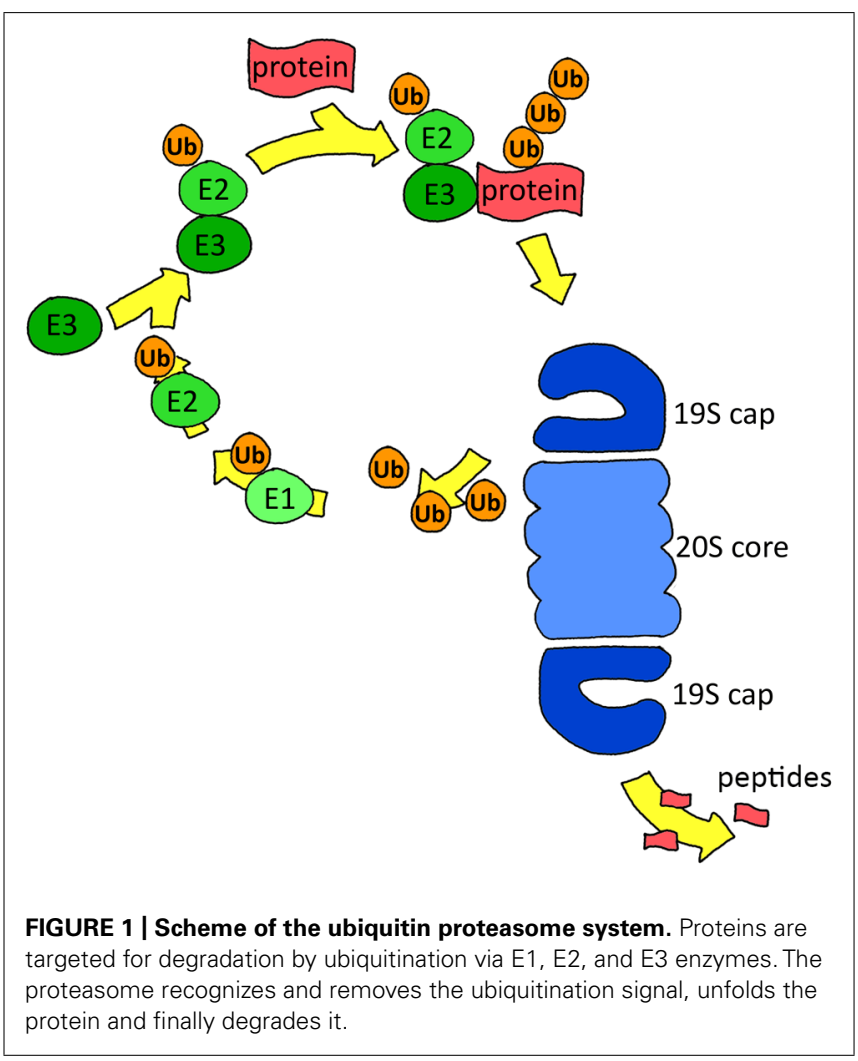

$(\beta 2)$, or chymotrypsin-like $(\beta 5)$ activity that cleave after negatively charged, positively charged, and hydrophobic amino acids, respectively (Lilienbaum, 2013). The 19 S regulatory complex recognizes and unfolds the ubiquitinated substrate and guides it into the 20S core. The 19S complex consists of 19 individual proteins, of which six are ATPases of the AAA family (Baumeister et al., 1998). Binding of ATP is necessary for assembly of the 20S core with the 19S cap, subsequently ATP hydrolysis is required for protein unfolding, while for the next steps, gate opening, translocation and degradation, only ATP binding is required (Smith et al., 2005).

Next to the 19S complex, also other regulatory proteasome activators (PA) exist, including 11S (PA28), PI31, and PA200, which bind the $20 \mathrm{~S}$ core in an ATP-independent way (Lilienbaum, 2013). PA28 $\alpha \beta$ expression is induced upon secretion of interferon gamma (IFN $\gamma$ ) and plays a role in processing peptides for MHC class I antigen presentation (Realini etal., 1994; Sijts and Kloetzel, 2011). When PA28 $\alpha \beta$ binds to $20 S$ core, the activities of all $\beta$-subunits are increased, which is probably due to an increased accessibility rather than alterations within the active sites themselves. In contrast to PA28 $\alpha \beta$, the exact mechanism that PA28 $\gamma$, which is only expressed in the nucleus, uses to exert its function is not known (Rechsteiner and Hill, 2005).

IFN $\gamma$ not only induces different PA caps but also induces the expression and incorporation of the proteasomal immunosubunits $\beta 1 \mathrm{i}$ (LMP2), $\beta 2 \mathrm{i}$ (Mecl-1), and $\beta 5 \mathrm{i}$ (LMP7) that substitute $\beta 1, \beta 2$, and $\beta 5$, respectively. With this replacement, the chymotrypsin-like activity increases and the immunoproteasome shows an altered cleavage pattern, resulting in different peptides being generated that are subsequently presented by MHC class-I molecules to the cells of the immune system (Sijts and Kloetzel, 2011; Basler et al., 2013).

\section{GLIAL CELLS}

Neuroglia were first described by the German pathologist Rudolf Virchow already more than 150 years ago. For a long time these cells were considered as nerve glue, a kind of connective tissue holding the brain together. In contrast to neurons, glia are not electrically excitable. This made it difficult to study these cells, and as a consequence, most neuroscientific research was focused on neuronal function. When sophisticated molecular tools became available which made it possible to study the physiology of glial cells, this has led to a change in the neurocentric view of neuroscientists. During the last decades, it has become evident that glial cells are essential for proper neuronal function, are actively involved in neuronal communication, and form the immune system of the brain. As diverse as different glial cells are in morphology and origin, as diverse they are likely in their function. They take care of the general homeostasis in the brain, insulate neurons, and protect against pathogenic invaders (Kettenmann and Verkhratsky, 2008). The ratio between neurons and glia in the human central nervous system (CNS) is about 1:1, with oligodendrocytes being the most abundant type of glial cells (75.6\%), followed by astrocytes (17.3\%) and microglia (6.5\%) in human male brains (Pelvig et al., 2008). Below, the most important glial cell types and their functions are described (Figure 2).

\section{ASTROCYTES}

Astrocytes perform a variety of crucial tasks in the CNS. Similar to neurons, astrocytes are of ectodermal origin. During the first stages of embryogenesis, the first astrocyte precursor cells arise from neural stem cells. These radial glia function as neural progenitors and form the scaffold that is used by immature neurons to migrate toward their final location. In a later stage, these cells give rise to the progenitors of oligodendrocytes as well as to the different kinds of astrocytes in the brain. The astrocyte population is broad and heterogeneous and the classification of subtypes is in its initial stage. Astrocytes contact multiple blood vessels with their endfeet, and they connect to neighboring astrocytes via gap junctions. Besides, astrocytes envelope multiple synapses and fibrous astrocytes in the white matter contact several nodes of Ranvier, which are the small gaps in myelinated axons (Sofroniew and Vinters, 2010; Molofsky et al., 2012). Subventricular astrocyte-like cells are the stem cells in the brain. The progeny of these cells migrate through the rostral migratory stream into the olfactory bulb, and differentiate into interneurons. When isolated and brought in culture, they can differentiate in both neurons and glia thus exhibiting multipotent properties (Mamber et al., 2013). These cells are even still present in aged brains, suggesting regenerative potential until late in life (Van Den Berge et al., 2010).

In the mature brain, astrocytes influence synaptic transmission directly by the release of gliotransmitters including glutamate, ATP, GABA, and D-serine, although it is not fully understood how the cells release these transmitters. Astrocytes also respond to neurotransmitters, which leads to a surge in 


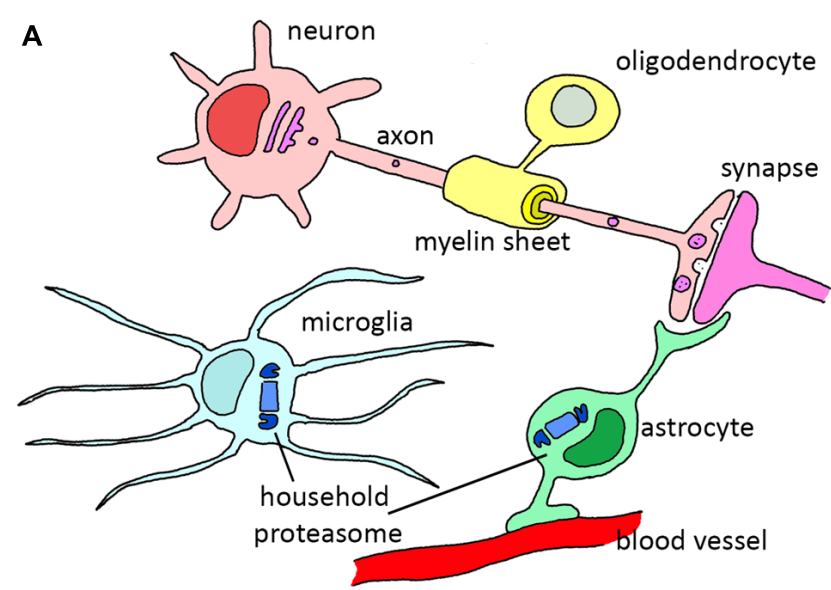

FIGURE 2 | The role of various glial cells in the healthy and diseased CNS. (A) In the healthy situation, astrocytes support neurons by filtering nutrients from the blood and modulating synapses, oligodendrocytes wrap axons in isolating myelin sheets and microglia scan the environment for dead cells or invading pathogens. (B) During reactive gliosis in neurodegenerative diseases, oligodendrocytes and astrocytes lose their normal support function.

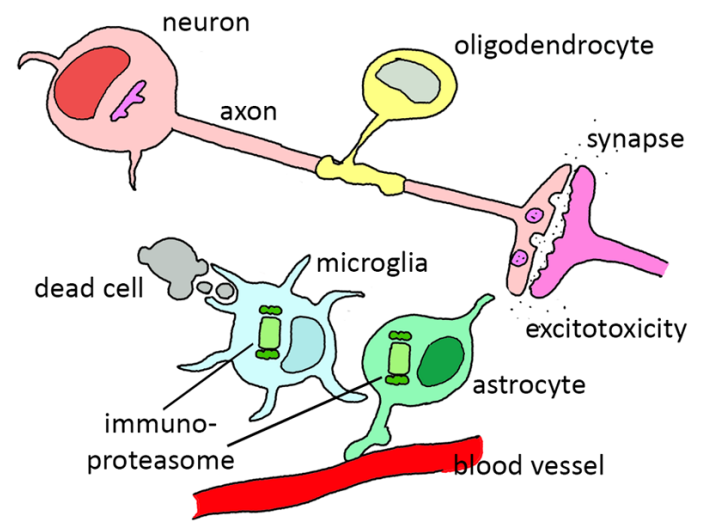

Astrocytes decrease glutamate uptake from the synapse, leading to excitotoxicity. Microglia become activated and phagocytize dead cells and start to secrete pro-inflammatory cytokines that activate astrocytes. Both reactive astrocytes and activated microglia upregulate immunoproteasome expression. In particular diseases, demyelination of the axons is observed due to oligodendrocyte dysfunction. calcium. Although astrocytes do have voltage-gated channels (Pappalardo et al., 2014), they are not able to respond with an increase in calcium in a millisecond time scale. Hence, astrocytes play a modulatory role: they are likely to influence synaptic communication of the many neurons in their domain. Astrocytes can also regulate synaptic transmission by mediating homeostasis of ions, $\mathrm{pH}$ and (neuro)transmitters. A well-known function of astrocytes is uptake of glutamate from the synaptic cleft via glutamate transporter Glt-1. Moreover, astrocytes contain transporters for the neurotransmitters GABA and glycine, for $\mathrm{K}^{+}$ ions, bicarbonate, water and monocarboxylic acid (Sofroniew and Vinters, 2010). Recently, it has been shown that astrocytes are able to influence synapses also by synaptic pruning both in the developing and in the adult mouse brain. This phagocytosis of synapses is dependent on neuronal activity and is mediated via the Mertk and Megf10 pathways. Thus, astrocytes actively contribute to activity-dependent synapse elimination and CNS remodeling (Chung et al., 2013). Next to the phagocytosis of synapses, activated astrocytes are able to phagocytize amyloid $\beta$ deposits in vitro and in situ (Wyss-Coray et al., 2003).

Furthermore, astrocytes form a key compartment of the blood brain barrier (BBB); they are not only involved in induction and development of the $\mathrm{BBB}$, they also regulate $\mathrm{BBB}$ permeability (Abbott, 2002). Astrocytes are connecting the blood vessels with many neuronal perikarya, axons and synapses. Therefore, astrocytes are the ideal cells to make an important contribution to the energy supply of the brain; for example by taking up glucose from the blood via their glucose transporters.

In conclusion, astrocytes are a heterogeneous group of glial cells that exert numerous tasks essential for proper neuronal function. They are indispensable in neurodevelopment, synaptic communication and brain homeostasis. As a consequence, loss or change in astrocyte function can contribute to pathogenesis of neurodegenerative diseases. A clear example is the leukodystrophy Alexander's disease, which is caused by a mutation in the astrocyte specific gene GFAP that leads to astrocyte pathology and dysfunction (Brenner et al., 2001; Sosunov et al., 2013).

\section{OLIGODENDROCYTES}

Oligodendrocytes are the myelinating cells of the brain, and form an insulating myelin sheath around the axonal segments of neurons. Like astrocytes, oligodendrocytes are of ectodermal origin; they arise from the neural stem cells in the neuroepithelium during early embryogenesis. The onset of myelination, as well as the selection of axons that require myelination, are both tightly regulated. Neuronal activity and degree of differentiation, together with several surface receptors (e.g., LINGO-1), influence the brain area and specific axons that are myelinated (Baumann and Pham-Dinh, 2001; Bradl and Lassmann, 2010). As oligodendrocytes have only a short time window wherein they are capable of myelination, this provides temporal control during early differentiation as well (Baumann and Pham-Dinh, 2001). A single oligodendrocyte can enwrap multiple axons, while a single axon can have adjacent myelin sheets belonging to different oligodendrocytes. Myelination of axons is important for a highspeed, reliable conduction of electrical signals between neurons. The myelinated fibers contain small gaps named nodes of Ranvier that are important for the fast signal conduction, so the action potential can jump from node to node. During the peak of myelination, about three times the weight of the oligodendrocyte is produced in myelin each day. Small changes in protein homeostasis will therefore have huge consequences for protein production and quality control, which can result in misfolding and accumulation of proteins and cause dysfunctional oligodendrocytes and eventually demyelination. Illustratively, transgenic 
rat overexpressing the oligodendrocyte proteolipid protein showed oligodendrocyte apoptosis and dysmyelination (Baumann and Pham-Dinh, 2001; Bradl and Lassmann, 2010). Axons can be remyelinated by new oligodendrocytes arising from the $\mathrm{NG}^{+}$ cells that are stimulated to divide and differentiate by activated microglia and astrocytes. However, the resulting myelin sheath is thinner, possibly due to the lack of stimulating growth factors that were initially secreted by the growing axon. Oligodendrocyte dysfunction is directly detrimental for neuronal function and leads to neurodegeneration in the $\alpha$-synucleinopathy multiple system atrophy (MSA), but also in multiple sclerosis and other leukodystrophies (Baumann and Pham-Dinh, 2001; Kuzdas et al., 2013).

\section{MICROGLIA}

Microglia primarily function as the immune cells of the CNS. In contrast to astrocytes and oligodendrocytes, microglia are from mesodermal origin (Ginhoux et al., 2010) and are derived from hematopoietic stem cells in the yolk sac early in embryonic development (Alliot etal., 1999). Although microglia are mostly known for their function in the immune response under disease conditions, they also play an important role in CNS homeostasis. During neuronal development, microglia regulate brain plasticity, by controlling synapses (Kettenmann et al., 2013). Next to phagocytizing apoptotic cells and pruning synapses during development, microglia are actively involved in promoting apoptosis, which is also an important aspect of neuronal development (Kettenmann et al., 2013). In the adult brain, microglia also phagocytize dead neurons and express several receptors for neurotransmitters, -peptides, and -modulators, thereby sensing (changes in) neuronal activity. Under healthy conditions, microglia have a small nucleus and long, thin, very motile processes, and although called "resting microglia," these cells are constantly monitoring the environment and when dying neurons are detected, microglia become activated. Subsequent phagocytosis is a tightly regulated process involving multiple receptors like CD36, lectin, and integrin receptors (Kettenmann etal., 2013).

Next to neuronal damage, invading pathogens are detected and cleaned up by microglia (Aloisi, 2001). To recognize and eliminate foreign entities, a variety of pattern recognition receptors are expressed including complement receptor 3 and toll-like receptors (TLR) 2, 4, and 9 that promote phagocytosis and recognize bacterial lipopolysaccharide (LPS; TLR2, 4) or DNA (TLR9). These cytokines are secreted by CNS associated macrophages, astrocytes and by other microglia as a paracrine activation mechanism. TNF$\alpha$, IL-1, and IFN $\gamma$ are pro-inflammatory cytokines that activate the immune functions of microglia including phagocytosis, cytokine production and antigen presentation. The immune response is regulated by anti-inflammatory cytokines such as IL-10, TGF- $\beta$, which downregulate the expression of proinflammatory cytokines, reactive oxygen species (ROS), chemokines and other molecules associated with phagocytosis in microglia (Aloisi, 2001; Tambuyzer et al., 2009).

\section{GLIA IN PATHOLOGY}

Early pathological studies showed astrogliosis and microglial proliferation in damaged brain tissues in several neurodegenerative diseases including Huntington's disease (HD; Faideau et al., 2010), Alzheimer's disease (AD; Sheng et al., 1997; Mrak, 2009), but also in inflammatory diseases, brain trauma, ischemia and infection (Gray et al., 1996; Tambuyzer et al., 2009; Amor et al., 2013; Pekny et al., 2014). Since microglia sense neuronal damage, they might be the initiators of the glial reaction to neuronal pathology, which is called neuroinflammation (reactive gliosis). Activated microglia have been shown to secrete cytokines that induce astrocyte reactivity. This is a delayed reaction; microglia are sensitive for the smallest pathological changes in the CNS, but only when the damage is severe enough this will lead to astrogliosis. Astrogliosis is characterized by increased expression of the astrocyte-specific intermediate filament GFAP (Pekny et al., 2014) and vimentin (Parpura et al., 2012). Astrocytes express cytokine receptors for, e.g., IL-1, IL6 , and TNF- $\alpha$, and microglia might disturb normal astrocyte function by activating astrocytes via these receptors. For example, TNF- $\alpha$ affects glutamate transmission directly by inhibiting expression of astrocytic glutamate transporters (Cumiskey et al., 2005). As a result of activation, astrocytes release cytokines that can in turn influence microglial function (Amor et al., 2013). Hereby a feedback loop is created, in which factors from both astrocytes and microglia regulate each other (Zhang et al., 2010).

It is unclear whether glial activation under pathological circumstances is beneficial or detrimental. Activation of astrocytes is initially meant to protect neurons by forming a protective border around the damaged site (Pekny et al., 2014), but loss-of-function of astrocytes such as reduced glutamate uptake may also result in neuronal dysfunction (Cumiskey et al., 2005). LPS-induced microglial activation is associated with subsequent astrocyte and oligondendrocyte impairment and demyelination. LPS induction of microglia caused a decrease in expression in several astrocytic proteins that are important for their normal function (e.g., Aqp4, a water transport channel). Astrocytes connect to each other and to oligodendrocytes via gap junctions, and activated astrocytes show reduced expression of connexins (30 and 43) that mediate these junctions. As ions, water and osmolites are exchanged via these connexins, loss of this connection leads to decreased oligodendrocyte function and subsequent demyelination and neuronal impairment (Sharma et al., 2010). In astrocytes, Dicer ablation causes changes in the transcriptome resulting in the upregulation of many immature/reactive astrocyte genes, while astrocytic genes related to mature astrocyte functions are downregulated (e.g., GLT-1). The alterations in astrocyte phenotype occur already before neuronal deficits were perceived, underlining the importance of proper astrocyte function in the brain (Tao et al., 2011).

\section{A DIVERGENCE IN UPS BETWEEN NEURONS AND GLIA}

Since glia are essential for proper neuronal function, disturbances in glial function can lead to excitotoxicity and neurodegeneration. However, in neurodegenerative diseases with protein inclusions (proteinopathies), neurons appear to be most vulnerable, as 
protein aggregation and cell degeneration is mainly observed in neurons. Possibly these differences are due to dissimilarities in their protein homeostasis. Indeed, distinct cell types show divergent protein synthesis and degradation (Vilchez et al., 2012). In addition, differences may exist in UPS levels and activity between neurons and the various glial cells. The UPS is the main protein complex involved in the degradation of oxidized proteins, and oxidation of nucleic acids, lipids and proteins is associated with aging and neurodegenerative diseases (Mariani et al., 2005). Proteasome inhibition causes an increase in nucleic acid oxidation in both primary neurons and astrocytes; however, this increase is much larger in neurons. This suggests that neurons are more sensitive to proteasome inhibition, or are more prone to oxidative stress, which is associated with neurodegenerative diseases like AD and Parkinson's disease (PD; Ding et al., 2004). The UPS appears to be less active in neurons in comparison to white matter glia (Tydlacka et al., 2008). Intriguingly, in response to cytokines such as TNF- $\alpha$, IL-2, G-CSF, and IFN $\gamma$, neurons upregulate the Ub-like protein ubiquitin D (or Fat10; Lisak etal., 2011), which is able to target long-lived proteins to the proteasome. Conversely, both astrocytes and microglia failed to upregulate Fat10 upon cytokine stimulation (Hipp et al., 2005), also indicating that the UPS is regulated in neurons in another way. In contrast to most other neurodegenerative diseases, in intranuclear inclusion body disease (INIBD) the largest proportion of aggregates are found in glial cells (about $5 \%$ in glial cells, compared to $1 \%$ in neurons). Here, most aggregates are present in astrocytes, and a smaller proportion in oligodendrocytes. All aggregates are positive for Ub, however, glial cells seem to have a significantly smaller proportion of aggregates positive for the Ub-like proteins NEDD8, NUB1, and SUMO1 than neurons. This slightly dissimilar composition of the aggregates can be explained by either variations in protein expression or protein recruitment toward the aggregates in the cell types (Mori et al., 2012). In conclusion, neurons and glia are differently reacting to proteasome inhibition and cytokines. Besides, presence of UPS components in inclusion bodies seem to diverge between neurons and glia, which could be indications why neurons are more vulnerable in neurodegenerative diseases.

\section{UPS IN GLIA IN RELATION TO NEURODEGENERATIVE DISEASES}

The tight balance between protein synthesis and degradation is essential for cellular function. In the brain, disturbances in either of the two cause the accumulation and aggregation of short-lived and misfolded proteins. In aging neurons, UPS activity has been shown to be decreased (Tydlacka et al., 2008), accordingly, age-related alterations in proteasomal activity are implicated in various neurodegenerative diseases (Tydlacka et al., 2008; Tashiro etal., 2012; Lin et al., 2013; Orre etal., 2013). It remains to be examined in more detail whether and how proteasome levels and activity differ between neurons and glia, which would obviously affect the capacity of cells to maintain proper protein homeostasis. In many diseases protein aggregates are hallmarks that are clearly visible in neurons, and are indicative for neuronal dysfunction. However, aggregates are also described in glial cells, for example in HD (Shin et al., 2005; Tong et al., 2014) and amyotrophic lateral sclerosis (ALS; Bruijn et al., 1997), although they are usually smaller or less abundant. The discrepancy between the occurrence of neuronal and glial inclusions implies that the UPS system is more efficient to remove aggregation-prone proteins in glia. Yet, while glia might be better able to handle these proteins, this does not mean that glia are not affected. Mainly astrocytes and microglia react to the increase of aggregated proteins in the brain and show altered function, thereby contributing to neuronal dysfunction. Many studies have shown that neuronal UPS dysfunction plays an important role in several neurodegenerative diseases. The first indications were found already more than 25 years ago, when components of the UPS were found in inclusions of several neurological diseases including PD, Pick's disease but also in Rosenthal fibers in astrocytomas (Lowe et al., 1988). Depletion of $26 \mathrm{~S}$ proteasome in mice neurons led to significant neurodegeneration and inclusion body formation (Bedford et al., 2008). Although the depletion was restricted to neurons, changes in glia were observed as astrocytes showed an increase in GFAP and vimentin protein expression, indicative of reactive gliosis (Elkharaz et al., 2013). Interestingly, astrocytes themselves seem to be less sensitive for proteasome inhibition. It has recently been suggested that this is due to the high expression of the heat shock protein HSP25 (Goldbaum et al., 2009). Although inhibition of proteasomes by the reversible proteasome inhibitor MG-132 caused aggresome formation and cytoskeletal disturbances in cultured primary astrocytes, cell viability was only diminished by $20 \%$. Besides, cytoskeletal disturbances appeared to be reversible in astrocytes, whereas in oligodendrocytes proteasome inhibition massively induced apoptosis. This effect might be caused by the induction of the HSP25, which is expressed at a much higher level in astrocytes and interacts with all three types of cytoskeletal filaments in astrocytes. As downregulation of this protein indeed resulted in fragmentation of actin networks, these results suggest a protective role of HSP25 in the astrocyte cytoskeleton during proteasome inhibition (Goldbaum et al., 2009). Proteasome inhibition does not only change cell viability, it has also been shown to decrease intermediate filament transcription in astrocyte cell lines. Treatment with proteasome inhibitors epoxomicin and MG-132 decreased the mRNA levels of the astrocyte-specific intermediate filament GFAP in different astrocyte cell lines. Similarly, vimentin and nestin expression were significantly decreased upon proteasome inhibition in astrocytes, but not in neuronal cells. Moreover, rat brains treated with proteasome inhibitors through a cannula showed less astrogliosis around the cannula. It appeared that the proteasome can affect GFAP promotor activity by the degradation of its transcription factors, thereby linking UPS activity directly to astrogliosis (Middeldorp et al., 2009).

Cultured primary oligodendrocytes seem to be much more sensitive to proteasome inhibition when compared to astrocytes. Treatment of these cells with MG-132 caused oxidative stress, mitochondrial dysfunction and apoptosis after $18 \mathrm{~h}$ (Goldbaum etal., 2006). While inhibition of the $26 \mathrm{~S}$ regulatory subunit 7 (RPT1, part of 19S) specifically reduced pro-inflammatory cytokine secretion in LPS-stimulated cultured 
microglia (Bi etal., 2012), in general also microglia showed a decreased survival and an increase in pro-inflammatory response following proteasome inhibition, including upregulation of nitric oxide and TNF- $\alpha$ secretion (Kwon et al., 2008). LPS induction also triggers the secretion of these cytokines by microglia, while intracellularly the pro-inflammatory $\mathrm{NF}-\kappa \mathrm{B}$ pathway is upregulated. This process is controlled by UPS components, with E3 ligase RING finger protein 11 (RNF11) as one of the key negative regulators of the NF- $\kappa \mathrm{B}$ pathway in microglia (Dalal etal., 2012). In neurons and microglia, IFN $\gamma$ caused induction of the immunoproteasome by replacing the constitutive subunits $\beta 1, \beta 2$, and $\beta 5$ with the inducible immuno subunits $\beta 1$, $\beta 2 \mathrm{i}$, and $\beta 5 \mathrm{i}$ and the association with the regulatory complex PA28 $\alpha \beta$. Synergistically, LPS-induced neuroinflammation can aggravate neurodegeneration that is triggered by proteasome inhibition (Stohwasser etal., 2000; Pintado et al., 2012).

Since both proteasome inhibition and neuroinflammation are associated with neurodegenerative diseases, studying the interplay between those two will provide new insights in neurodegenerative disease mechanisms. In the following section, proteasome dysfunction and its effect on glia in several age-related neurodegenerative diseases are described and in Table $\mathbf{1}$ an overview of the literature on a wider range of neurodegenerative diseases is given.

\section{ALZHEIMER'S DISEASE}

Alzheimer's disease is the most prevalent form of dementia and is characterized by irreversible memory loss and impaired cognitive functions. Magnetic resonance imaging (MRI) scans of $\mathrm{AD}$ patient brains reveal atrophy and an enlargement of the ventricles caused by neuronal shrinkage or cell loss, and loss of (synaptic) connections is thought to be the main contributor to the cognitive and memory impairments (Bozzali et al., 2011). Neuropathological hallmarks of AD are senile plaques and neurofibrillary tangles. Neurofibrillary tangles are formed by the hyperphosphorylated microtubule-associated protein tau and are located mainly inside neurons, while extracellular the senile plaques consist of aggregates formed by the peptide amyloid $\beta(\mathrm{A} \beta)$. Over the last two decades, the concept of a neuroinflammatory involvement in $\mathrm{AD}$ has been established. This started in 1986 with the discovery of plaque-associated reactive microglia, and additional studies described the association of both activated microglia and astrocytes with $\mathrm{A} \beta$ plaques expressing pro-inflammatory markers (Rozemuller et al., 1986; Griffin et al., 1989; Mrak, 2009). Astrocytes change their phenotype when contacting extracellular $A \beta$, and their response includes upregulation of glial fibrillary acidic protein (GFAP), vimentin and S100ß (Griffin et al., 1989; Kamphuis etal., 2012). In AD, both astrocytes and microglia play an important role in clearance of $A \beta$ plaques (Wyss-Coray et al., 2003; Mandrekar et al., 2009; Mulder etal., 2014). Besides, attenuation of astrocyte

Table 1 | Overview of published data on the role of glia and the UPS in several neurodegenerative diseases.

\begin{tabular}{|c|c|}
\hline Disease & Aggregation in glia \\
\hline Alzheimer's disease and other tauopathies & $\begin{array}{l}\text { Tau in astrocytes and oligodendrocytes } \\
\text { (Ferrer et al., 2014) }\end{array}$ \\
\hline Huntington's disease & $\begin{array}{l}\text { Htt in astrocytes (Shin et al., 2005; Tydlacka } \\
\text { et al., 2008; Tong et al., 2014) }\end{array}$ \\
\hline Parkinson's disease and other $\alpha$-synucleopathies & $\begin{array}{l}\text { a-syn in oligodendrocytes and possibly } \\
\text { astrocytes (Casarejos et al., 2009; } \\
\text { Stefanova et al., 2012; Pasanen et al., 2014) }\end{array}$ \\
\hline Amyotrophic lateral sclerosis & $\begin{array}{l}\text { SOD1 and C9orf72 in astrocytes, microglia } \\
\text { and oligodendrocytes (Bruijn et al., 1997; } \\
\text { Forsberg etal., 2011; Mizielinska et al., } \\
\text { 2013) } \\
\text { TDP-43 in oligodendrocytes (Brettschneider } \\
\text { et al., 2013) }\end{array}$ \\
\hline Multiple sclerosis & No aggregates \\
\hline
\end{tabular}

\section{UPS changes}

Immunoproteasome induction in astrocytes and microglia (Mishto etal., 2006; Nijholt et al., 2011; Orre et al., 2013)

Immunoproteasome induction in neurons (Díaz-Hernández et al., 2003)

No changes

Immunoproteasome induction in astrocytes, microglia, oligodendrocytes and neurons. (Puttaparthi et al., 2007; Cheroni et al., 2009; Bendotti etal., 2012)

TDP-43 aggregates are Ub positive (Zhang et al., 2008)

Immunoproteasome induction in astrocytes, microglia, neurons and lymphocytes (Mishto et al., 2010; Zheng et al., 2012; Popescu et al., 2013; Bellavista et al., 2014)

Alexander's disease GFAP and TDP-43 in astrocytes in Rosenthal fibers (Brenner et al., 2001; Cho Impaired proteasome function in astrocytes (Tang et al., 2006, 2010) 
activation leads to a higher plaque load and increased microglial activation, probably as a compensatory mechanism (Kraft et al., 2013). A loss in metabolic function of activated astrocytes worsens the disease, and upregulation of GFAP has been shown to correlate with downregulation of the astrocyte-specific glutamate transporter EAAT2 (Simpson et al., 2010; Yan et al., 2013).

Changes in the UPS pathway have been associated with AD in several studies. Ub is accumulating in both plaques and tangles (Chu etal., 2000). Next to the regular Ub protein in the brains of $\mathrm{AD}$ and Down syndrome patients, both having the plaque pathology, a unique form of ubiquitin $B$ can be found. This protein originates from a frameshift mutation in the mRNA and leads to a protein with an aberrant C-terminus, called $\mathrm{UBB}+1$. It can be detected in all $\mathrm{AD}$ and Down syndrome patients, but in none of the non-demented controls (van Leeuwen etal., 1998). Because of the absence of the carboxyterminal Gly-76, UBB +1 cannot ubiquitinate other proteins, but is itself efficiently ubiquitinated. However, the proteasome seems unable to degrade large amounts $\mathrm{UBB}+1$, leading to proteasome inhibition (Lam et al., 2000; van Tijn et al., 2007). In addition, $\mathrm{UBB}+1$ expression also changes the immune response in astrocytes upon TNF- $\alpha$ and IFN $\gamma$ treatment as secretion of the chemokines CCL2 and CXCL8 is increased dramatically. This is probably due to an upregulation of several proteins in the NF- $\mathrm{B}$ and JNK pathways, suggesting that a disruption in the UPS directly influences pro-inflammatory signaling in astrocytes and vice versa (Choi et al., 2013).

Importantly, alterations in the UPS can influence the degradation of $A \beta$ in both neurons and astrocytes. Although mainly the neuronal viability is affected in response to increasing $A \beta$ levels, also astrocytes showed a similar upregulation in UPS related proteins and a decrease in proteasome activities upon $\mathrm{A} \beta$ treatment as neurons (Lopez Salon et al., 2003). Treatment with $\mathrm{A} \beta$ oligomers decreased proteasome activity in vitro and in mouse brain lysates, and a lower proteasome activity was also observed in lysates of several brain areas of $\mathrm{AD}$ patients (Gregori et al., 1995; Keller et al., 2000; Tseng et al., 2008; Zhao and Yang, 2010). However, these measurements were mainly performed in whole brain homogenates or in (neuronal) cell lines, and may therefore fail to see alterations in immunoproteasome levels and activity in glial cells since that was not investigated in these studies. More recently, it was shown that $\mathrm{A} \beta$ treatment led to an increase in proteasome activity in both cultured neurons, astrocytes and microglia. In addition, it was discovered that both mRNA and protein levels of immunoproteasome subunits $\beta 5 \mathrm{i}$ and $\beta 1 \mathrm{i}$ were upregulated in reactive astrocytes and microglia around plaques in $\mathrm{AD}$ mice and human $\mathrm{AD}$ patient material, whereas in $\mathrm{AD}$ mice the levels of $\beta 2 \mathrm{i}$ were similar to controls. Consistently, the activity of all immunoproteasome subunits was increased with increasing plaque load in both $\mathrm{AD}$ mice and in post-mortem material of human $\mathrm{AD}$ patients (Nijholt et al., 2011; Orre etal., 2013). These results are in line with earlier data showing that $\beta 1 \mathrm{i}$ expression levels in neurons and astrocytes were increased with age, and in the brain areas most affected in AD (Mishto et al., 2006). While it becomes clear that especially immunoproteasome activity is increased in glia during $\mathrm{AD}$, it remains to be examined whether these changes are beneficial or not.

\section{PARKINSON'S DISEASE}

Parkinson's disease is after AD the most common neurodegenerative disease with an incidence of $0.3 \%$ in the total population. The incidence increases with age leading to $4 \%$ of people above the age of 80 suffering from this mostly idiopathic movement disorder (Imai et al., 2000; de Lau and Breteler, 2006). The etiology of the disease is not known, although there are some familial cases caused by mutations in the genes of, e.g., alpha-synuclein ( $\alpha$-syn) and E3 ligase parkin. Also mutations in UCH-L1, a Ub c-terminal hydrolase, have been associated with PD but this finding is controversial (Hardy et al., 2009). In PD, the dopaminergic neurons in the substantia nigra pars compacta degenerate, which is accompanied with eosinophillic intracytoplasmatic inclusions known as Lewy bodies (LBs) and gliosis. While microgliosis is dominantly present in PD, reactive astrogliosis is virtually absent (Mirza et al., 1999; Van Den Berge etal., 2010; Halliday and Stevens, 2011). Although they do not change their phenotype, astrocytes are affected by $\alpha$-syn accumulation. Astrocytes are able to take up $\alpha$-syn released from neurons, and subsequently secrete proinflammatory cytokines (TNF- $\alpha$ and CXCL1), thereby activating microglia (Lee et al., 2010). These results were confirmed in a study using a mouse model expressing $\alpha$-syn in astrocytes only, which caused similar disease symptoms, astrocyte functional loss and activated microglia. As the pro-inflammatory response of these cells caused neurodegeneration (Gu et al., 2010), this suggests that glial dysfunction plays a significant role in the etiology of PD.

A role for the UPS in PD was first described in familial PD when it was discovered that mutations in the protein parkin were associated with familial PD. Parkin functions as a Ub ligase in association with proteasomal degradation (Imai et al., 2000). A subset of the mutations in parkin, but also post-translational modifications of the protein, have been shown to cause a loss of function of the E3 ligase, and have been associated with UPS impairment and abrogation of the neuroprotective effects of parkin (Tsai et al., 2003; Yamamoto et al., 2005; Ali et al., 2011). In addition, Lewy bodies are mainly composed of $\alpha$-syn and cytoskeletal proteins, but next to these proteins Lewy bodies contain the UPS related proteins parkin and Ub (Shults, 2006). Induced mutant $\alpha$-syn expression was reported to decrease proteasome activity in cultured cells and a decreased proteasome activity was detected in the substantia nigra of PD patients (Tanaka et al., 2001; McNaught et al., 2003). These findings are in contrast with a study that showed that overall proteasome activity was not decreased in brain regions with Lewy body pathology (Tofaris et al., 2003). The discrepancy between these results can be explained by the technique that was used to measure proteasome activity in these studies. The AMC-peptides are rather non-specific since also other proteases can cleave these peptides, thereby influencing the results. Therefore, the exact role of UPS in PD is still under debate. Cultured parkin knock-out neurons appeared to be more resistant to mild proteasome inhibition than wild type neurons due to upregulation of anti-oxidant scavenger protein glutathione and autophagy-related proteins. In contrast, parkin knock-out glia (mixed population, mainly astrocytes) were more susceptible to 
epoxomicin-induced cell death than wild type glia, suggesting that parkin dysfunction in PD mainly affects glia. In contrast to neurons, this effect on parkin knock-out glia was associated with lower levels of glutathione, a decreased HSP70 response, and an increase in poly-ubiquitinated proteins, all contributing to glial dysfunction. Besides, conditioned medium of parkin knock-out glia was less neuroprotective. So proteasome inhibition causes glial dysfunction and is therefore possibly the reason for the pathology in Parkin knock-out mice (Solano et al., 2008; Casarejos et al., 2009). Correspondingly, proteasome inhibitors had deleterious effects in mice expressing $\alpha$-syn only in oligodendrocytes. The mice showed motor symptoms and severe degeneration in the nigrostriatal pathway caused by myelin disruption and demyelination in oligodendrocytes that had accumulated $\alpha$-syn fibrils in their cytoplasm (Stefanova et al., 2012). Overall in PD, inhibition of the UPS system seems to contribute to glial dysfunction, thereby also affecting neuronal function. However, similar to $\mathrm{AD}$ the exact mechanism causing proteasome changes and neurodegeneration still needs to be unraveled.

\section{HUNTINGTON'S DISEASE}

$\mathrm{HD}$ is a severe familial neurodegenerative disease typified by chorea (abnormal involuntary limb movements), incoordination, cognitive decline, and behavioral difficulties (Walker, 2007). The prevalence of this autosomal dominant heritable disease is five to seven affected individuals per 100,000 people in the Western world. HD is characterized by neuronal and glial aggregates, neuronal dysfunction and neurodegeneration, starting in the striatum and the cerebral cortex (corticostriatal pathway). An individual is affected when the polyglutamine (polyQ) repeat present in the disease-related huntingtin (HTT) protein exceed 36-41 glutamines (Walker, 2007). The encoding CAG repeats are not unique for $\mathrm{HD}$ as at least eight other neurodegenerative disorders are caused by a similar polyQ expansion in different proteins. Although the cause is already known for decades, the exact disease mechanism is still unclear. Interestingly, even though every cell in the body expresses the polyQ-expanded proteins, mainly neurons are affected and degenerate (Han et al., 2010). Fragments of the polyQ-expanded HTT are thought to initiate aggregation, and the resulting protein aggregates or inclusion bodies (IB) are an important hallmark of HD. More recently it became clear that these IBs are not necessarily causing neurodegeneration, as the formation of IBs did not correlate with cell death in cultured striatal neurons (Saudou et al., 1998). The formation of IBs may even be a protection mechanism of the cell to sequester toxic monomers and oligomers, thereby promoting cell survival (Arrasate et al., 2004; Truant et al., 2008).

Intriguingly, glial cells hardly show aggregates in HD patient material, while the expanded HTT is also expressed in these cells (Shin etal., 2005). Still, neuropathological studies show glial involvement in HD by phagocytosis of dead neurons and activated astrocytes (Reddy et al., 1998; Li et al., 2003), and the severity of both astrogliosis and microgliosis correlates with disease progression (Sapp et al., 2001; Faideau et al., 2010). Increased GFAP expression and activated microglia are already observed in presymptomatic stages in $\mathrm{HD}$ patients. With increased aggregation in neurons also the number of activated microglia and astrocytes increases (Sapp et al., 2001; Faideau et al., 2010). In addition, both microglial cell lines expressing polyQ-expanded HTT and primary microglia from early postnatal HD mice were strongly impaired in their migration toward chemotactic stimuli, and showed a retarded response to laser-induced brain injury in vivo (Kwan et al., 2012). This suggests that polyQ-expanded HTT expression influences the appearance and function of reactive microglia. Similarly, astrocytes showed a loss of their regulatory functions: in the R6/2 HD mouse model decreased levels of glutamate transporters and glutamate uptake were observed, eventually leading to excitotoxicity (Shin et al., 2005). Intriguingly, excitotoxicity also occurred when polyQ-expanded HTT is only expressed in striatal astrocytes but not in neurons (Faideau et al., 2010; Wang et al., 2012). In addition, astrocytes isolated from R6/2 mice suppressed the secretion of the chemokine CCL5/RANTES and of BDNF, which is a growth factor important for neuronal survival, thereby inhibiting the trophic functions of astrocytes (Chou et al., 2008). So despite the low abundance of IBs, exclusive expression of polyQ-expanded HTT in astrocytes caused a decrease in glutamate uptake followed by excitotoxicity, neurodegeneration and an age-dependent HD-like phenotype in mice (Bradford et al., 2009), suggesting a crucial role for astrocytes in HD that is directly affected by polyQ-expanded HTT. As astrocytes and microglia hardly show IB formation in HD and when they appear, they are much smaller in size (Shin et al., 2005), differences in HTT ubiquitination or proteasome activity might explain these dissimilarities.

An important role for the UPS in HD was suggested in the late nineties, when $\mathrm{Ub}$ and proteasomes were found to be colocalized with HTT aggregates as shown by immunohistochemistry in HD mice and post-mortem patient material (Davies etal., 1997; DiFiglia etal., 1997). This led to the hypothesis that components of the UPS were irreversibly sequestered into HTT aggregates, as was also suggested by FRAP studies that showed no fluorescence recovery after photobleaching in fluorescently tagged proteasomes that were present in aggregates (Holmberg etal., 2004). However, we recently showed with fluorescent pulse-chase experiments that proteasomes were exchanged in HTT aggregates but with slower kinetics than it would be detectable by FRAP analysis (Schipper-Krom etal., 2014). This indicates that proteasomes are dynamically recruited into HTT aggregates. Since soluble HTT can be ubiquitinated, HTT can be targeted for proteasomal degradation (Thompson et al., 2009; Juenemann etal., 2013). However, various studies have reported an impairment of the proteasome system in both HD cell models and in the brain of HD patients (Seo et al., 2004; Hunter et al., 2007). Moreover, impairment of the proteasome causes accumulation of the potentially toxic aggregation-prone N-terminal HTT fragments (Li et al., 2010). Yet, proteasomes are able to degrade polyQ-expanded HTT fragments efficiently and entirely, but only when HTT is efficiently targeted for degradation by ubiquitination (Juenemann et al., 2013). Together these results suggest a crucial role for the UPS in HD pathogenesis.

Cellular stress due to polyQ-expanded HTT in neurons can lead to proteasome subunit changes, as increased levels of the IFN $\gamma$-inducible immunoproteasome subunits LMP2 and LMP7 
were observed in cortex and striatum of both HD mice and post-mortem HD patient material. Interestingly, this increase was mainly attributed to degenerating neurons (Díaz-Hernández et al., 2003), and may be the result of glial cytokine secretion. It is unknown whether glial cells upregulate immunoproteasomes in $\mathrm{HD}$, and whether the induction of the immunoproteasome is beneficial in HD. While these proteasomes are better capable to deal with protein aggregates under oxidative stress (Seifert et al., 2010), it is unknown whether immunoproteasomes are also better capable to degrade polyQ-expanded HTT fragments. Still, the apparent absence of HTT aggregates in glial cells remains intriguing, and may be explained by observed differences in proteasome activity in wild type mouse brains where glial cells showed increased proteasome activity when compared to neurons. It remains, however, to be examined whether this explains the differences in aggregate size and abundance. Remarkably, when polyQ-expanded HTT was present in R6/2 mice, proteasome activity levels were not altered (Tydlacka et al., 2008), although this does not reflect any possible changes in proteasome composition. The latter finding is underscored by a recent study, where it was shown by using proteasome activity-based probes that proteasomes recruited into aggregates were accessible for substrates and remained active. Besides, no differences were observed in overlay proteasome activity between HD and wild type mice (Schipper-Krom et al., 2014). Together, this indicates that the overall activity of the proteasome does not change in $\mathrm{HD}$, although the composition of proteolytic subunits undergoes some alterations. Therefore, studying the role of the UPS in glial cells in HD is of high importance.

\section{AMYOTROPHIC LATERAL SCLEROSIS}

Amyotrophic lateral sclerosis is a late onset, rapidly progressive and ultimately fatal neurological disorder, characterized by muscle weakness and atrophy leading to the inability to control voluntary movements. These symptoms are caused by the loss of motor neurons in the brain and spinal cord. Prevalence is increasing with age from overall 4-6 cases per 100,000 to up to 33 cases per 100,000 in 60-75-year-olds. About $10 \%$ of these patients have the familial form of ALS, often caused by mutations in the gene coding for copper-zinc superoxide dismutase (SOD1; Majoor-Krakauer et al., 2003). Motor neuron degeneration is often preceded by the formation of nuclear inclusions containing ALS associated proteins SOD1, TDP-43. or FUS and are usually also Ub positive (Leigh et al., 1991; Bendotti et al., 2012). Glial pathology is strongly present in ALS as observed in cell models, mice and post-mortem patient material (Alexianu et al., 2001; Petrik et al., 2007; Evans et al., 2013). Although SOD1 expression in microglia or astrocytes alone is not sufficient to cause ALS phenotype in mice, transplantation of healthy microglia in SOD1 mutated mice slows down disease progression (Gong et al., 2000; Clement et al., 2003; Beers et al., 2006). In addition, SOD1 expression alone in motor neurons does not cause ALS pathology, suggesting that glial function is important in ALS development (Pramatarova et al., 2001). Normally, astrocytes are secreting numerous trophic factors, like VEGF and BNDF to promote neuronal survival, and they take up glutamate from the synaptic cleft. However, activated astrocytes in ALS showed disturbances in these functions, eventually leading to excitotoxicity (Trotti et al., 1999; Evans et al., 2013). Recently, it was shown that a mutation in C9orf72 could lead to aggregates in neurons, astrocytes, microglia and oligodendrocytes (Mizielinska et al., 2013). Besides, affected astrocytes caused neuronal cell death when co-cultured, suggesting an important role of astrocytes in this disease (Meyer et al., 2014). Microglia have been shown to secrete IL-1 $\beta$ as a response to purified mutant SOD1 stimulation, which is thus an important pro-inflammatory trigger (Meissner et al., 2010). Also secretion of several other pro-inflammatory cytokines such as TFN- $\alpha$, IFN $\gamma$, and IL-6 was reported, resulting in (more) activation of astrocytes and microglia (Evans et al., 2013).

Similar to the neurodegenerative diseases described above also impairment of several components of the UPS is observed in ALS, which is likely a cause or consequence of the protein aggregates that are widely present (Kabashi et al., 2008; Bendotti et al., 2012). Impairment of the UPS but not of the autophagic pathway led to ALS-like symptoms in mice. Conditional knock-out of the 19S proteasome subunit RPT3 specifically in motor neurons caused accumulation of ALS related proteins (FUS and TDP-43) in these cells, and led to reactive gliosis and motor dysfunction. A knock-out of autophagy associated gene Atg5 only led to accumulations of Ub and p62 in the cytoplasm but not of ALS-related proteins (Tashiro et al., 2012). While impairment of the UPS in motor neurons induced an ALS-like phenotype, immunohistochemical studies showed significantly increased levels of Ub and proteasome subunits in both motor neurons and astrocytes in ALS (Aquilano et al., 2003; Mendonça et al., 2006). This contradictory result could be explained by findings in an ALS mouse model where a decrease in constitutive proteasome and an increase in immunoproteasome levels were observed, which correlated with the glia-mediated inflammatory response. Also the levels of the reactive astrocyte marker GFAP, the microglia marker CD68, and secretion of the cytokine TNF- $\alpha$ were upregulated in the ALS mice in a presymptomatic stage (Cheroni et al., 2009). Motor neurons in ALS also showed an upregulation of PA28 $\alpha \beta$ which could lead to a decrease in the turnover of ubiquitinated proteins as this requires the $19 \mathrm{~S}$ activator (Bendotti et al., 2012). However, when mutant SOD1 mice were crossed with $\beta 1 \mathrm{i} / \mathrm{LMP} 2$ knockout mice, the absence of immunoproteasomes in vivo could not significantly prevent mutant SOD1-induced disease; as no changes in disease symptoms were observed (Puttaparthi et al., 2007). So while activated astrocytes and microglia secrete cytokines that result in the induction of immunoproteasomes in both glia and neurons, these changes seem to be not beneficial in the clearance of accumulating SOD1 proteins.

\section{CONCLUDING REMARKS AND FUTURE PERSPECTIVES}

Studies on the role of the UPS in neurodegenerative disease are mainly focusing on neurons, as these diseases are often considered to be cell autonomous due to the fact that neurons appear to be the most severe affected. Recently, however, the role of glial cells in neurodegenerative diseases is emerging. The fact that glial activation can already be observed in early presymptomatic stages advocates for an important if not crucial role for glial cells in the initiation of these diseases (Tai et al., 2007; Faideau et al., 2010). Glial cells express most of the disease-related proteins, and glial 
aggregates are observed in some of these neurodegenerative diseases albeit with lower frequencies (Bruijn et al., 1997; Shin et al., 2005; Tong et al., 2014). In addition, the disease-causing proteins can alter glial function by the induction of secretion of various cytokines. This makes glial cells important players in the various diseases, as the interplay between disease-causing proteins and the altered UPS not only affects glial cell homeostasis, but indirectly also neuronal function. A common hallmark of the here discussed various neurodegenerative diseases is the general downregulation of the constitutive proteasome accompanied by an upregulated immunoproteasome. This is in line with the observed phenotypical alterations that microglia and astrocytes undergo during disease progression, and the resulting pro-inflammatory environment correlates perfectly with the induction of the immunoproteasome. The induced immunoproteasomes may be better able to degrade intracellular protein aggregates, as suggested for protein aggregates that are induced following IFN $\gamma$-induced stress (Seifert et al., 2010). Since IFN $\gamma$ is secreted by microglia (Kawanokuchi et al., 2006) and is able to activate both microglia and astrocytes in several neurodegenerative diseases (Choi et al., 2013; Evans et al., 2013), most likely the observed immunoproteasome induction is mediated by microglia. Nevertheless, while immunoproteasomes are directly induced by IFN $\gamma$, this cytokine also induces the accumulation of oxidized proteins that may accelerate aggregation and affect protein homeostasis in time. Still, the induced immunoproteasomes appear better capable to degrade polyubiquitinated proteins under these circumstances, and proteolytic activity of immunoproteasomes is higher compared to standard proteasomes (Seifert et al., 2010). These data suggest that activation of glia and induction of the immunoproteasome may be beneficial for clearing disease-causing proteins.

Yet, similar to chronic activation of glia, it is unknown whether induction of the immunoproteasome is on the long term beneficial or detrimental in neurodegenerative diseases. After all, the increased immunoproteasome induction in these diseases and in aging could also indicate undesirable protein accumulation and chronic inflammation (Díaz-Hernández et al., 2003; Mishto et al., 2006; Cheroni et al., 2009; Nijholt et al., 2011; Orre et al., 2013; Bellavista et al., 2014). When the induction of the immunoproteasome is not beneficial in targeting the accumulating proteins, specific inhibitors targeting immunoproteasome subunits could be an efficient therapeutic approach. Although several of these inhibitors are already developed (Miller et al., 2013), more insight is required in the exact function of the immunoproteasome in these disorders.

Next to focusing on proteasome activity, for future approaches it is also important to examine which other alterations in the UPS observed in glia can be used as possible therapeutic targets. Although proteasome compositional changes appear in glial cells during disease progression, in general proteasomes stay active and accessible even in cells showing large protein aggregates (Tydlacka et al., 2008; Basler et al., 2013; Orre et al., 2013; Schipper-Krom et al., 2014). Yet, it is unclear whether the diseased proteins are correctly targeted for degradation, as inefficient ubiquitination of mutant and misfolded proteins could explain the observed protein accumulations and neuronal vulnerability. Improved targeting of the disease-causing proteins toward the proteasome by modifying ubiquitination (or with other Ub-like proteins) would increase their degradation and delay onset of disease. It is unknown whether the ubiquitination patterns of the various disease-related proteins in glia and neurons is dissimilar and whether they change during disease progression. Therefore, determining the ubiquitination patterns of these proteins in different stages of disease in both neurons and glia, along with determining the involved specific ubiquitin ligases and DUBs in these cells should lead to the identification of new and more specific therapeutic targets.

\section{ACKNOWLEDGMENTS}

This work was supported by an AMC PhD scholarship (Anne H. P. Jansen), the Internationale Stichting Alzheimer Onderzoek [ISAO 08504 and 12509 to Elly M. Hol], and the Netherlands Organization for Scientific Research [NWO; VICI grant 865.09.003 to Elly M. Hol].

\section{REFERENCES}

Abbott, N. J. (2002). Astrocyte-endothelial interactions and blood-brain barrier permeability. J. Anat. 200, 629-638. doi: 10.1046/j.1469-7580.2002.00064.x

Alexianu, M. E., Kozovska, M., and Appel, S. H. (2001). Immune reactivity in a mouse model of familial ALS correlates with disease progression. Neurology 57, 1282-1289. doi: 10.1212/WNL.57.7.1282

Ali, S. F., Binienda, Z. K., and Imam, S. Z. (2011). Molecular aspects of dopaminergic neurodegeneration: gene-environment interaction in Parkin dysfunction. Int. J. Environ. Res. Public Health 8, 4702-4713. doi: 10.3390/ijerph8124702

Alliot, F., Godin, I., and Pessac, B. (1999). Microglia derive from progenitors, originating from the yolk sac, and which proliferate in the brain. Dev. Brain Res. 117, 145-152. doi: 10.1016/S0165-3806(99)00113-3

Aloisi, F. (2001). Immune function of microglia. Glia 36, 165-179. doi: 10.1002/glia.1106

Amor, S., Peferoen, L. A., Vogel, D. Y., Breur, M., Van Der Valk, P., Baker, D., et al. (2013). Inflammation in neurodegenerative diseases - an update. Immunology 142, 151-166. doi: 10.1111/imm.12233

Aquilano, K., Rotilio, G., and Ciriolo, M. R. (2003). Proteasome activation and nNOS down-regulation in neuroblastoma cells expressing a $\mathrm{Cu}, \mathrm{Zn}$ superoxide dismutase mutant involved in familial ALS. J. Neurochem. 85, 1324-1335. doi: 10.1046/j.1471-4159.2003.01783.x

Arrasate, M., Mitra, S., Schweitzer, E. S., Segal, M. R., and Finkbeiner, S. (2004). Inclusion body formation reduces levels of mutant huntingtin and the risk of neuronal death. Nature 431, 805-810. doi: 10.1038/nature02998

Basler, M., Kirk, C. J., and Groettrup, M. (2013). The immunoproteasome in antigen processing and other immunological functions. Curr. Opin. Immunol. 25, 74-80. doi: 10.1016/j.coi.2012.11.004

Baumann, N., and Pham-Dinh, D. (2001). Biology of oligodendrocyte and myelin in the mammalian central nervous system. Physiol. Rev. 81, 871-927.

Baumeister, W., Walz, J., Zühl, F., and Seemüller, E. (1998). The proteasome: paradigm of a self-compartmentalizing protease. Cell 92, 367-380. doi: 10.1016/S0092-8674(00)80929-0

Bedford, L., Hay, D., Devoy, A., Paine, S., Powe, D. G., Seth, R., et al. (2008). Depletion of $26 \mathrm{~S}$ proteasomes in mouse brain neurons causes neurodegeneration and Lewy-like inclusions resembling human pale bodies. J. Neurosci. 28, 81898198. doi: 10.1523/JNEUROSCI.2218-08.2008

Beers, D. R., Henkel, J. S., Xiao, Q., Zhao, W., Wang, J., Yen, A. A., et al. (2006). Wild-type microglia extend survival in PU.1 knockout mice with familial amyotrophic lateral sclerosis. Proc. Nati. Acad. Sci. U.S.A. 103, 16021-16026. doi: 10.1073/pnas.0607423103

Bellavista, E., Santoro, A., Galimberti, D., Comi, C., Luciani, F., and Mishto, M. (2014). Current understanding on the role of standard and immunoproteasomes in inflammatory/immunological pathways of multiple sclerosis. Autoimmune Dis. 2014, 739705. doi: 10.1155/2014/739705

Bendotti, C., Marino, M., Cheroni, C., Fontana, E., Crippa, V., Poletti, A., et al. (2012). Dysfunction of constitutive and inducible ubiquitin-proteasome system in amyotrophic lateral sclerosis: implication for protein aggregation and 
immune response. Prog. Neurobiol. 97, 101-126. doi: 10.1016/j.pneurobio.2011. 10.001

Bi, W., Jing, X., Zhu, L., Liang, Y., Liu, J., Yang, L., et al. (2012). Inhibition of $26 \mathrm{~S}$ protease regulatory subunit 7 (MSS1) suppresses neuroinflammation. PLoS ONE 7:e36142. doi: 10.1371/journal.pone.0036142

Bozzali, M., Padovani, A., Caltagirone, C., and Borroni, B. (2011). Regional grey matter loss and brain disconnection across Alzheimer disease evolution. Curr. Med. Chem. 18, 2452-2458. doi: 10.2174/092986711795843263

Bradford, J., Shin, J., Roberts, M., Wang, C., Li, X., and Li, S. (2009). Expression of mutant huntingtin in mouse brain astrocytes causes age-dependent neurological symptoms. Proc. Natl. Acad. Sci. U.S.A. 106, 22480-22485. doi: 10.1073/pnas.0911503106

Bradl, M., and Lassmann, H. (2010). Oligodendrocytes: biology and pathology. Acta Neuropathol. 119, 37-53. doi: 10.1007/s00401-009-0601-5

Brenner, M., Johnson, A. B., Boespflug-Tanguy, O., Rodriguez, D., Goldman, J. E., and Messing, A. (2001). Mutations in Gfap, encoding glial fibrillary acidic protein, are associated with Alexander disease. Nat. Genet. 27, 117-120. doi: $10.1038 / 83679$

Brettschneider, J., Del Tredici, K., Toledo, J. B., Robinson, J. L., Irwin, D. J., Grossman, M., et al. (2013). Stages of pTDP-43 pathology in amyotrophic lateral sclerosis. Ann. Neurol. 74, 20-38. doi: 10.1002/ana.23937

Bruijn, L. I., Becher, M. W., Lee, M. K., Anderson, K. L., Jenkins, N. A., Copeland, N. G., et al. (1997). ALS-linked SOD1 mutant G85R mediates damage to astrocytes and promotes rapidly progressive disease with SOD1-containing inclusions. Neuron 18, 327-338. doi: 10.1016/S0896-6273(00)80272-X

Casarejos, M. J., Solano, R. M., Rodriguez-Navarro, J. A., Gómez, A., Perucho, J., Castaño, J. G., etal. (2009). Parkin deficiency increases the resistance of midbrain neurons and glia to mild proteasome inhibition: the role of autophagy and glutathione homeostasis. J. Neurochem. 110, 1523-1537. doi: 10.1111/j.1471-4159.2009.06248.x

Cheroni, C., Marino, M., Tortarolo, M., Veglianese, P., De Biasi, S., Fontana, E., et al. (2009). Functional alterations of the ubiquitin-proteasome system in motor neurons of a mouse model of familial amyotrophic lateral sclerosis. Hum. Mol. Genet. 18, 82-96. doi: 10.1093/hmg/ddn319

Cho, W., and Messing, A. (2009). Properties of astrocytes cultured from GFAP over-expressing and GFAP mutant mice. Exp. Cell Res. 315, 1260-1272. doi: 10.1016/j.yexcr.2008.12.012

Choi, K., Park, J., Lee, J., Han, E. C., and Choi, C. (2013). Mutant ubiquitin attenuates interleukin-1beta- and tumor necrosis factor-alpha-induced pro-inflammatory signaling in human astrocytic cells. PLoS ONE 8:e67891. doi: 10.1371/journal.pone.0067891

Chou, S. Y., Weng, J. Y., Lai, H. L., Liao, F., Sun, S. H., Tu, P. H., et al. (2008). Expanded-polyglutamine huntingtin protein suppresses the secretion and production of a chemokine (CCL5/RANTES) by astrocytes. J. Neurosci. 28 3277-3290. doi: 10.1523/JNEUROSCI.0116-08.2008

Chu, C. T., Caruso, J. L., Cummings, T. J., Ervin, J., Rosenberg, C., and Hulette, C. M. (2000). Ubiquitin immunochemistry as a diagnostic aid for community pathologists evaluating patients who have dementia. Mod. Pathol. 13, 420-426. doi: 10.1038/modpathol.3880072

Chung, W. S., Clarke, L. E., Wang, G. X., Stafford, B. K., Sher, A., Chakraborty, C., et al. (2013). Astrocytes mediate synapse elimination through MEGF10 and MERTK pathways. Nature 504, 394-400. doi: 10.1038/nature12776

Clement, A. M., Nguyen, M. D., Roberts, E. A., Garcia, M. L., Boillée, S. Rule, M., et al. (2003). Wild-type nonneuronal cells extend survival of SOD1 mutant motor neurons in ALS mice. Science 302, 113-117. doi: 10.1126/science. 1086071

Cumiskey, D., O'Connor, J. J., and Pickering, M. (2005). Actions of TNF-alpha on glutamatergic synaptic transmission in the central nervous system. Exp. Physiol. 90, 663-670. doi: 10.1113/expphysiol.2005.030734

Dalal, N. V., Pranski, E. L., Tansey, M. G., Lah, J. J., Levey, A. I., and Betarbet, R. S. (2012). RNF11 modulates microglia activation through NF- $\kappa$ B signalling cascade. Neurosci. Lett. 528, 174-179. doi: 10.1016/j.neulet.2012.08.060

Davies, S. W., Turmaine, M., Cozens, B. A., Difiglia, M., Sharp, A. H., Ross, C. A., et al. (1997). Formation of neuronal intranuclear inclusions underlies the neurological dysfunction in mice transgenic for the HD mutation. Cell 90, 537-548. doi: 10.1016/S0092-8674(00)80513-9

de Lau, L. M., and Breteler, M. M. (2006). Epidemiology of Parkinson's disease. Lancet Neurol. 5, 525-535. doi: 10.1016/S1474-4422(06)70471-9
Díaz-Hernández, M., Hernández, F., Martín-Aparicio, E., Gómez-Ramos, P., Morán, M. A., Castaño, J. G., et al. (2003). Neuronal induction of the immunoproteasome in Huntington's disease. J. Neurosci. 23, 11653-11661.

DiFiglia, M., Sapp, E., Chase, K. O., Davies, S. W., Bates, G. P., Vonsattel, J. P., et al. (1997). Aggregation of huntingtin in neuronal intranuclear inclusions and dystrophic neurites in brain. Science 277, 1990-1993. doi: 10.1126/science.277.5334.1990

Ding, Q., Dimayuga, E., Markesbery, W. R., and Keller, J. N. (2004). Proteasome inhibition increases DNA and RNA oxidation in astrocyte and neuron cultures. J. Neurochem. 91, 1211-1218. doi: 10.1111/j.1471-4159.2004. 02802.x

Elkharaz, J., Ugun-Klusek, A., Constantin-Teodosiu, T., Lawler, K., Mayer, R. J., Billett, E., et al. (2013). Implications for oxidative stress and astrocytes following $26 \mathrm{~S}$ proteasomal depletion in mouse forebrain neurones. Biochim. Biophys. Acta 1832, 1930-1938. doi: 10.1016/j.bbadis.2013.07.002

Evans, M. C., Couch, Y., Sibson, N., and Turner, M. R. (2013). Inflammation and neurovascular changes in amyotrophic lateral sclerosis. Mol. Cell. Neurosci. 53, 34-41. doi: 10.1016/j.mcn.2012.10.008

Faideau, M., Kim, J., Cormier, K., Gilmore, R., Welch, M., Auregan, G., et al. (2010). In vivo expression of polyglutamine-expanded huntingtin by mouse striatal astrocytes impairs glutamate transport: a correlation with Huntington's disease subjects. Hum. Mol. Genet. 19, 3053-3067. doi: 10.1093/hmg/ ddq2 212

Ferrer, I., Lopez-Gonzalez, I., Carmona, M., Arregui, L., Dalfo, E., TorrejonEscribano, B., et al. (2014). Glial and neuronal tau pathology in tauopathies: characterization of disease-specific phenotypes and tau pathology progression. $J$. Neuropathol. Exp. Neurol. 73, 81-97. doi: 10.1097/NEN.0000000000000030

Forsberg, K., Andersen, P. Marklund, S. L., and Brannstrom, T. (2011). Glial nuclear aggregates of superoxide dismutase-1 are regularly present in patients with amyotrophic lateral sclerosis. Acta Neuropathol. 121, 623-634. doi: 10.1007/s00401-011-0805-3

Ginhoux, F., Greter, M., Leboeuf, M., Nandi, S., See, P., Gokhan, S., et al. (2010). Fate mapping analysis reveals that adult microglia derive from primitive macrophages. Science 330, 841-845. doi: 10.1126/science.1194637

Glickman, M. H., and Ciechanover, A. (2002). The ubiquitin-proteasome proteolytic pathway: destruction for the sake of construction. Physiol. Rev. 82, 373-428. doi: 10.1152/physrev.00027.2001

Goldbaum, O., Riedel, M., Stahnke, T., and Richter-Landsberg, C. (2009). The small heat shock protein HSP25 protects astrocytes against stress induced by proteasomal inhibition. Glia 57, 1566-1577. doi: 10.1002/glia.20870

Goldbaum, O., Vollmer, G., and Richter-Landsberg, C. (2006). Proteasome inhibition by MG-132 induces apoptotic cell death and mitochondrial dysfunction in cultured rat brain oligodendrocytes but not in astrocytes. Glia 53, 891-901. doi: 10.1002/glia.20348

Gong, Y. H., Parsadanian, A. S., Andreeva, A., Snider, W. D., and Elliott, J. L. (2000) Restricted expression of $\mathrm{G} 86 \mathrm{R} \mathrm{Cu} / \mathrm{Zn}$ superoxide dismutase in astrocytes results in astrocytosis but does not cause motoneuron degeneration. J. Neurosci. 20, 660-665.

Gray, F., Scaravilli, F., Everall, I., Chretien, F., An, S., Boche, D., et al (1996). Neuropathology of early HIV-1 infection. Brain Pathol. 6, 1-15. doi: 10.1111/j.1750-3639.1996.tb00775.x

Gregori, L., Fuchs, C., Figueiredo-Pereira, M. E., Van Nostrand, W. E., and Goldgaber, D. (1995). Amyloid $\beta$-protein inhibits ubiquitin-dependent protein degradation in vitro. J. Biol. Chem. 270, 19702-19708. doi: $10.1074 /$ jbc. 270.34 .19702

Griffin, W. S., Stanley, L. C., Ling, C., White, L., Macleod, V., Perrot, L. J., et al. (1989). Brain interleukin 1 and S-100 immunoreactivity are elevated in Down syndrome and Alzheimer disease. Proc. Natl. Acad. Sci. U.S.A. 86, 7611-7615. doi: 10.1073/pnas.86.19.7611

Gu, X. L., Long, C. X., Sun, L., Xie, C., Lin, X., and Cai, H. (2010) Astrocytic expression of Parkinson's disease-related A53T alpha-synuclein causes neurodegeneration in mice. Mol. Brain 3, 12. doi: 10.1186/17566606-3-12

Halliday, G. M., and Stevens, C. H. (2011). Glia: initiators and progressors of pathology in Parkinson's disease. Mov. Disord. 26, 6-17. doi: 10.1002/mds.23455

Han, I., You, Y., Kordower, J. H., Brady, S. T., and Morfini, G. A. (2010). Differential vulnerability of neurons in Huntington's disease: the role of cell typespecific features. J. Neurochem. 113, 1073-1091. doi: 10.1111/j.1471-4159.2010. 06672.x 
Hardy, J., Lewis, P., Revesz, T., Lees, A., and Paisan-Ruiz, C. (2009). The genetics of Parkinson's syndromes: a critical review. Curr. Opin. Genet. Dev. 19, 254-265. doi: 10.1016/j.gde.2009.03.008

Hipp, M. S., Kalveram, B., Raasi, S., Groettrup, M., and Schmidtke, G. (2005). FAT10, a ubiquitin-independent signal for proteasomal degradation. Mol. Cell. Biol. 25, 3483-3491. doi: 10.1128/MCB.25.9.3483-3491.2005

Holmberg, C. I., Staniszewski, K. E., Mensah, K. N., Matouschek, A., and Morimoto, R. I. (2004). Inefficient degradation of truncated polyglutamine proteins by the proteasome. EMBO J. 23, 4307-4318. doi: 10.1038/sj.emboj. 7600426

Hunter, J. M., Lesort, M., and Johnson, G. V. W. (2007). Ubiquitin-proteasome system alterations in a striatal cell model of Huntington's disease. J. Neurosci. Res. 85, 1774-1788. doi: 10.1002/jnr.21287

Imai, Y., Soda, M., and Takahashi, R. (2000). Parkin suppresses unfolded protein stress-induced cell death through its E3 ubiquitin-protein ligase activity. J. Biol. Chem. 275, 435661-435664. doi: 10.1074/jbc C000447200

Juenemann, K., Schipper-Krom, S., Wiemhoefer, A., Kloss, A., Sanz Sanz, A., and Reits, E. A. J. (2013). Expanded polyglutamine-containing N-terminal huntingtin fragments are entirely degraded by mammalian proteasomes. J. Biol. Chem. 288, 27068-27084. doi: 10.1074/jbc.M113.486076

Kabashi, E., Agar, J. N., Hong, Y., Taylor, D. M., Minotti, S., Figlewicz, D. A., et al. (2008). Proteasomes remain intact, but show early focal alteration in their composition in a mouse model of amyotrophic lateral sclerosis. J. Neurochem 105, 2353-2366. doi: 10.1111/j.1471-4159.2008.05317.x

Kamphuis, W., Orre, M., Kooijman, L., Dahmen, M., and Hol, E. M. (2012). Differential cell proliferation in the cortex of the APPswePS1dE9 Alzheimer's disease mouse model. Glia 60, 615-629. doi: 10.1002/ glia. 22295

Kawanokuchi, J., Mizuno, T., Takeuchi, H., Kato, H., Wang, J., Mitsuma, N., et al. (2006). Production of interferon-gamma by microglia. Mult. Scler. 12, 558-564. doi: $10.1177 / 1352458506070763$

Keller, J. N., Hanni, K. B., and Markesbery, W. R. (2000). Impaired proteasome function in Alzheimer's Disease. J. Neurochem. 75, 436-439. doi: 10.1046/j.14714159.2000.0750436.x

Kettenmann, H., Kirchhoff, F., and Verkhratsky, A. (2013). Microglia: new roles for the synaptic stripper. Neuron 77, 10-18. doi: 10.1016/j.neuron.2012.12.023

Kettenmann, H., and Verkhratsky, A. (2008). Neuroglia: the 150 years after. Trends Neurosci. 31, 653-659. doi: 10.1016/j.tins.2008.09.003

Kraft, A. W., Hu, X., Yoon, H., Yan, P., Xiao, Q., Wang, Y., et al. (2013). Attenuating astrocyte activation accelerates plaque pathogenesis in APP/PS1 mice. FASEB J. 27, 187-198. doi: 10.1096/fj.12-208660

Kuzdas, D., Stemberger, S., Gaburro, S., Stefanova, N., Singewald, N., and Wenning, G. K. (2013). Oligodendroglial alpha-synucleinopathy and MSA-like cardiovascular autonomic failure: experimental evidence. Exp. Neurol. 247, 531-536. doi: 10.1016/j.expneurol.2013.02.002

Kwan, W., Trager, U., Davalos, D., Chou, A., Bouchard, J., Andre, R., et al. (2012). Mutant huntingtin impairs immune cell migration in Huntington disease. J. Clin. Invest. 122, 4737-4747. doi: 10.1172/JCI64484

Kwon, S., Ahn, T., Yoon, M., and Jeon, B. S. (2008). Bv-2 stimulation by lactacystin results in a strong inflammatory reaction and apoptotic neuronal death in SH-SY5Y cells. Brain Res. 1205, 116-121. doi: 10.1016/j.brainres.2008. 02.030

Lam, Y. A., Pickart, C. M., Alban, A., Landon, M., Jamieson, C., Ramage, R., et al. (2000). Inhibition of the ubiquitin-proteasome system in Alzheimer's disease. Proc. Natl. Acad. Sci. U.S.A. 97, 9902-9906. doi: 10.1073/pnas.170173897

Lee, H., Suk, J., Patrick, C., Bae, E., Cho, J., Rho, S., et al. (2010). Direct transfer of a-synuclein from neuron to astroglia causes inflammatory responses in synucleinopathies. J. Biol. Chem. 285, 9262-9272. doi: 10.1074/jbc.M109. 081125

Leigh, P. N., Whitwell, H., Garofalo, O., Buller, J., Swash, M., Martin, J. E., et al. (1991). Ubiquitin-immunoreactive intraneuronal inclusions in amyotrophic lateral sclerosis. Morphology, distribution, and specificity. Brain J. Neurol. 114, 775-788. doi: 10.1093/brain/114.2.775

Li, S., Yu, Z., Li, C., Nguyen, H., Zhou, Y., Deng, C., et al., (2003). Lack of huntingtin-associated protein-1 causes neuronal death resembling hypothalamic degeneration in Huntington's disease. J. Neurosci. 23, 6956-6964.
Li, X., Wang, C., Huang, S., Xu, X., Li, X., Li, H., et al. (2010). Inhibiting the ubiquitin-proteasome system leads to preferential accumulation of toxic Nterminal mutant huntingtin fragments. Hum. Mol. Genet. 19, 2445-2455. doi: $10.1093 / \mathrm{hmg} / \mathrm{ddq} 127$

Lilienbaum, A. (2013). Relationship between the proteasomal system and autophagy. Int. J. Biochem. Mol. Biol. 4, 1-26.

Lin, Z., Zhao, D., and Yang, L. (2013). Interaction between misfolded PrP and the ubiquitin-proteasome system in prion-mediated neurodegeneration. Acta Biochim. Biophys. Sin. 45, 477-484. doi: 10.1093/abbs/gmt020

Lisak, R. P., Nedelkoska, L., Studzinski, D., Bealmear, B., Xu, W., and Benjamins, J. A. (2011). Cytokines regulate neuronal gene expression: differential effects of Th1, Th2 and monocyte/macrophage cytokines. J. Neuroimmunol. 238, 19-33. doi: 10.1016/j.jneuroim.2011.06.010

Lopez Salon, M., Pasquini, L., Besio Moreno, M., Pasquini, J. M., and Soto, E. (2003). Relationship between $\beta$-amyloid degradation and the $26 \mathrm{~S}$ proteasome in neural cells. Exp. Neurol. 180, 131-143. doi: 10.1016/S0014-4886(02)00060-2

Lowe, J., Blanchard, A., Morrell, K., Lennox, G., Reynolds, L., Billett, M., et al. (1988). Ubiquitin is a common factor in intermediate filament inclusion bodies of diverse type in man, including those of Parkinson's disease, Pick's disease, and Alzheimer's disease, as well as Rosenthal fibres in cerebellar astrocytomas, cytoplasmic bodies in muscle, and mallory bodies in alcoholic liver disease. $J$. Pathol. 155, 9-15. doi: 10.1002/path.1711550105

Majoor-Krakauer, D., Willems, P., and Hofman, A. (2003). Genetic epidemiology of amyotrophic lateral sclerosis. Clin. Genet. 63, 83-101. doi: 10.1046/j.00099163.2002.00001.x

Mamber, C., Kozareva, D. A., Kamphuis, W., and Hol, E. M. (2013). Shades of gray: the delineation of marker expression within the adult rodent subventricular zone. Prog. Neurobiol. 111, 1-16. doi: 10.1016/j.pneurobio.2013.07.003

Mandrekar, S., Jiang, Q., Lee, C. Y., Koenigsknecht-Talboo, J., Holtzman, D. M., and Landreth, G. E. (2009). Microglia mediate the clearance of soluble Abeta through fluid phase macropinocytosis. J. Neurosci. 29, 4252-4262. doi: 10.1523/JNEUROSCI.5572-08.2009

Mariani, E., Polidori, M. C., Cherubini, A., and Mecocci, P. (2005). Oxidative stress in brain aging, neurodegenerative and vascular diseases: an overview. J. Chromatogr. 827, 65-75. doi: 10.1016/j.jchromb.2005.04.023

McNaught, K. S., Belizaire, R., Isacson, O., Jenner, P., and Olanow, C. W. (2003). Altered proteasomal function in sporadic Parkinson's disease. Exp. Neurol. 179, 38-46. doi: 10.1006/exnr.2002.8050

Meissner, F., Molawi, K., and Zychlinsky, A. (2010). Mutant superoxide dismutase 1-induced IL-1ß accelerates Als pathogenesis. Proc. Natl. Acad. Sci. U.S.A. 107, 13046-13050. doi: 10.1073/pnas.1002396107

Mendonça, D. M. F., Chimelli, L., and Martinez, A. M. B. (2006). Expression of ubiquitin and proteasome in motorneurons and astrocytes of spinal cords from patients with amyotrophic lateral sclerosis. Neurosci. Lett. 404, 315-319. doi: 10.1016/j.neulet.2006.06.009

Meyer, K., Ferraiuolo, L., Miranda, C. J., Likhite, S., Mcelroy, S., Renusch, S., et al. (2014). Direct conversion of patient fibroblasts demonstrates non-cell autonomous toxicity of astrocytes to motor neurons in familial and sporadic ALS. Proc. Natl. Acad. Sci. U.S.A. 111, 829-832. doi: 10.1073/pnas.1314085111

Middeldorp, J., Kamphuis, W., Sluijs, J. A., Achoui, D., Leenaars, C. H. C., Feenstra, M. G., et al. (2009). Intermediate filament transcription in astrocytes is repressed by proteasome inhibition. FASEB J. 23, 2710-2726. doi: 10.1096/fj.08-127696

Miller, Z., Ao, L., Kim, K. B., and Lee, W. (2013). Inhibitors of the immunoproteasome: current status and future directions. Curr. Pharm. Des. 19, 4140-4151. doi: $10.2174 / 1381612811319220018$

Mirza, B., Hadberg, H., Thomsen, P., and Moos, T. (1999). The absence of reactive astrocytosis is indicative of a unique inflammatory process in Parkinson's disease. Neuroscience 95, 425-432. doi: 10.1016/S0306-4522(99)00455-8

Mishto, M., Bellavista, E., Ligorio, C., Textoris-Taube, K., Santoro, A., Giordano, M., et al. (2010). Immunoproteasome LMP2 60HH variant alters MBP epitope generation and reduces the risk to develop multiple sclerosis in Italian female population. PLoS ONE 5:e9287. doi: 10.1371/journal.pone.0009287

Mishto, M., Bellavista, E., Santoro, A., Stolzing, A., Ligorio, C., Nacmias, B., etal. (2006). Immunoproteasome and LMP2 polymorphism in aged and Alzheimer's disease brains. Neurobiol. Aging 27, 54-66. doi: 10.1016/j.neurobiolaging.2004.12.004

Mizielinska, S., Lashley, T., Norona, F. E., Clayton, E. L., Ridler, C. E., Fratta, P., et al. (2013). C9orf72 frontotemporal lobar degeneration is characterised by frequent 
neuronal sense and antisense RNA foci. Acta Neuropathol. 126, 845-857. doi: 10.1007/s00401-013-1200-z

Molofsky, A. V., Krenick, R., Ullian, E., Tsai, H., Deneen, B., Richardson, W. D., et al. (2012). Astrocytes and disease: a neurodevelopmental perspective. Genes Dev. 26, 891-907. doi: 10.1101/gad.188326.112

Mori, F., Tanji, K., Odagiri, S., Hattori, M., Hoshikawa, Y., Kono, C., et al. (2012). Ubiquitin-related proteins in neuronal and glial intranuclear inclusions in intranuclear inclusion body disease. Pathol. Int. 62, 407-411. doi: 10.1111/j.1440-1827.2012.02812.x

Mrak, R. E. (2009). Neuropathology and the neuroinflammation idea. J. Alzheimers Dis. 18, 473-481. doi: 10.3233/JAD-2009-1158

Mulder, S. D., Nielsen, H. M., Blankenstein, M. A., Eikelenboom, P., and Veerhuis, R. (2014). Apolipoproteins $\mathrm{E}$ and $\mathrm{J}$ interfere with amyloid-beta uptake by primary human astrocytes and microglia in vitro. Glia 62, 493-503. doi: 10.1002/glia.22619

Nijholt, D. A., De Graaf, T. R., Van Haastert, E. S., Oliveira, A. O., Berkers, C. R., Zwart, R., et al. (2011). Endoplasmic reticulum stress activates autophagy but not the proteasome in neuronal cells: implications for Alzheimer's disease. Cell Death Differ. 18, 1071-1081. doi: 10.1038/cdd.2010.176

Orre, M., Kamphuis, W., Dooves, S., Kooijman, L., Chan, E. T., Kirk, C. J., et al. (2013). Reactive glia show increased immunoproteasome activity in Alzheimer's disease. Brain 136, 1415-1431. doi: 10.1093/brain/awt083

Pappalardo, L. W., Samad, O. A., Black, J. A., and Waxman, S. G. (2014). Voltagegated sodium channel $\mathrm{Na} 1.5$ contributes to astrogliosis in an in vitro model of glial injury via reverse $\mathrm{Na} / \mathrm{Ca}$ exchange. Glia 62, 1162-1175. doi: 10.1002/ glia.22671

Parpura, V., Heneka, M. T., Montana, V., Oliet, S. H. R., Schousboe, A., Haydon, P. G., et al. (2012). Glial cells in (patho)physiology. J. Neurochem. 121, 4-27. doi: 10.1111/j.1471-4159.2012.07664.x

Pasanen, P., Myllykangas, L., Siitonen, M., Raunio, A., Kaakkola, S., Lyytinen, J., et al. (2014). A novel $\alpha$-synuclein mutation A53E associated with atypical multiple system atrophy and Parkinson's disease-type pathology. Neurobiol. Aging 35, 2180. doi: 10.1016/j.neurobiolaging.2014.03.024

Pekny, M., Wilhelmsson, U., and Pekna, M. (2014). The dual role of astrocyte activation and reactive gliosis. Neurosci. Lett. 565, 30. doi: 10.1016/j.neulet.2013.12.071

Pelvig, D. P., Pakkenberg, H., Stark, A. K., and Pakkenberg, B. (2008). Neocortical glial cell numbers in human brains. Neurobiol. Aging 29, 1754-1762. doi: 10.1016/j.neurobiolaging.2007.04.013

Petrik, M. S., Wilson, J. M., Grant, S. C., Blackband, S. J., Tabata, R. C., Shan, X., et al. (2007). Magnetic resonance microscopy and immunohistochemistry of the CNS of the mutant Sod murine model of ALS reveals widespread neural deficits. Neuromolecular Med. 9, 216-229. doi: 10.1007/s12017-007$8002-1$

Pintado, C., Gavilan, M. P., Gavilan, E., Garcia-Cuervo, L., Gutierrez, A., Vitorica, J., et al. (2012). Lipopolysaccharide-induced neuroinflammation leads to the accumulation of ubiquitinated proteins and increases susceptibility to neurodegeneration induced by proteasome inhibition in rat hippocampus. J. Neuroinflammation 9, 87. doi: 10.1186/17422094-9-87

Popescu, B. F., Pirko, I., and Lucchinetti, C. F. (2013). Pathology of multiple sclerosis: where do we stand? Continuum (Minneapolis, Minn.) 19, 901-921. doi: 10.1212/01.CON.0000433291.23091.65

Pramatarova, A., Laganiere, J., Roussel, J., Brisebois, K., and Rouleau, G. A. (2001). Neuron-specific expression of mutant superoxide dismutase 1 in transgenic mice does not lead to motor impairment. J. Neurosci. 21, 3369-3374.

Puttaparthi, K., Van Kaer, L., and Elliott, J. L. (2007). Assessing the role of immunoproteasomes in a mouse model of familial ALS. Exp. Neurol. 206, 53-58. doi: 10.1016/j.expneurol.2007.03.024

Realini, C., Dubiel, W., Pratt, G., Ferrell, K., and Rechsteiner, M. (1994). Molecular cloning and expression of a gamma-interferoninducible activator of the multicatalytic protease. J. Biol. Chem. 269, 20727-20732.

Rechsteiner, M., and Hill, C. P. (2005). Mobilizing the proteolytic machine: cell biological roles of proteasome activators and inhibitors. Trends Cell Biol. 15, 27-33. doi: 10.1016/j.tcb.2004.11.003

Reddy, P. H., Williams, M., Charles, V., Garrett, L., Pike-Buchanan, L., Whetsell, W. O., et al. (1998). Behavioural abnormalities and selective neuronal loss in HD transgenic mice expressing mutated full-length HD cDNA. Nat. Genet. 20, 198-202. doi: $10.1038 / 2510$
Rock, K. L., Gramm, C., Rothstein, L., Clark, K., Stein, R., Dick, L., et al. (1994) Inhibitors of the proteasome block the degradation of most cell proteins and the generation of peptides presented on MHC class I molecules. Cell 78, 761-771. doi: 10.1016/S0092-8674(94)90462-6

Rozemuller, J. M., Eikelenboom, P., and Stam, F. C. (1986). Role of microglia in plaque formation in senile dementia of the Alzheimer type. An immunohistochemical study. Virchows Arch. B Cell Pathol. Incl. Mol. Pathol. 51, 247-254. doi: 10.1007/BF02899034

Sapp, E., Kegel, K. B., Aronin, N., Hashikawa, T., Uchiyama, Y., Tohyama, K., et al. (2001). Early and progressive accumulation of reactive microglia in the Huntington disease brain. J. Neuropathol. Exp. Neurol. 60, 161-172.

Saudou, F., Finkbeiner, S., Devys, D., and Greenberg, M. E. (1998). Huntingtin acts in the nucleus to induce apoptosis but death does not correlate with the formation of intranuclear inclusions. Cell 95, 55-66. doi: 10.1016/S0092-8674(00)81782-1

Schipper-Krom, S., Juenemann, K., Jansen, A. H., Wiemhoefer, A., Van Den Nieuwendijk, R., Smith, D. L., et al. (2014). Dynamic recruitment of active proteasomes into polyglutamine initiated inclusion bodies. FEBS Lett. 588, 151-159. doi: 10.1016/j.febslet.2013.11.023

Seifert, U., Bialy, L. P., Ebstein, F., Bech-Otschir, D., Voigt, A., Schröter, F., et al. (2010). Immunoproteasomes preserve protein homeostasis upon interferoninduced oxidative stress. Cell 142, 613-624. doi: 10.1016/j.cell.2010.07.036

Seo, H., Sonntag, K., and Isacson, O. (2004). Generalized brain and skin proteasome inhibition in Huntington's disease. Ann. Neurol. 56, 319-328. doi: 10.1002/ana.20207

Sharma, R., Fischer, M. T., Bauer, J., Felts, P. A., Smith, K. J., Misu, T., et al. (2010). Inflammation induced by innate immunity in the central nervous system leads to primary astrocyte dysfunction followed by demyelination. Acta Neuropathol. 120, 223-236. doi: 10.1007/s00401-010-0704-Z

Sheng, J. G., Mrak, R. E., and Griffin, W. S. (1997). Neuritic plaque evolution in Alzheimer's disease is accompanied by transition of activated microglia from primed to enlarged to phagocytic forms. Acta Neuropathol. 94, 1-5. doi: 10.1007/s004010050664

Shin, J. Y., Fang, Z. H., Yu, Z. X., Wang, C. E., Li, S. H., and Li, X. J. (2005). Expression of mutant huntingtin in glial cells contributes to neuronal excitotoxicity. J. Cell Biol. 171, 1001-1012. doi: 10.1083/jcb.200508072

Shults, C. W. (2006). Lewy bodies. Proc. Natl. Acad. Sci. U.S.A. 103, 1661-1668. doi: 10.1073/pnas.0509567103

Sijts, E. J., and Kloetzel, P. M. (2011). The role of the proteasome in the generation of MHC class I ligands and immune responses. Cell. Mol. Life Sci. 68, 1491-1502. doi: 10.1007/s00018-011-0657-y

Simpson, J. E., Ince, P. G., Lace, G., Forster, G., Shaw, P. J., Matthews, F., et al. (2010). Astrocyte phenotype in relation to Alzheimer-type pathology in the ageing brain. Neurobiol. Aging 31, 578-590. doi: 10.1016/j.neurobiolaging.2008. 05.015

Smith, D. M., Kafri, G., Cheng, Y., Ng, D., Walz, T., and Goldberg, A. L. (2005). ATP binding to PAN or the $26 \mathrm{~S}$ ATPases causes association with the $20 \mathrm{~S}$ proteasome, gate opening, and translocation of unfolded proteins. Mol. Cell. 20, 687-698. doi: 10.1016/j.molcel.2005.10.019

Sofroniew, M. V., and Vinters, H. V. (2010). Astrocytes: biology and pathology. Acta Neuropathol. 119, 7-35. doi: 10.1007/s00401-009-0619-8

Solano, R. M., Casarejos, M. J., Menéndez-Cuervo, J., Rodriguez-Navarro, J. A., García De Yébenes, J., and Mena, M. A. (2008). Glial dysfunction in Parkin null mice: effects of aging. J. Neurosci. 28, 598-611. doi: 10.1523/JNEUROSCI.460907.2008

Sosunov, A. A., Guilfoyle, E., Wu, X., Mckhann, G. M. 2nd, and Goldman, J. E. (2013). Phenotypic conversions of "protoplasmic" to "reactive" astrocytes in Alexander disease. J. Neurosci. 33, 7439-7450. doi: 10.1523/JNEUROSCI.450612.2013

Stefanova, N., Kaufmann, W. A., Humpel, C., Poewe, W., and Wenning, G. K. (2012). Systemic proteasome inhibition triggers neurodegeneration in a transgenic mouse model expressing human alpha-synuclein under oligodendrocyte promoter: implications for multiple system atrophy. Acta Neuropathol. 124, 51-65. doi: 10.1007/s00401-012-0977-5

Stohwasser, R., Giesebrecht, J., Kraft, R., Müller, E., Häusler, K. G., Kettenmann, H., et al. (2000). Biochemical analysis of proteasomes from mouse microglia: induction of immunoproteasomes by interferon- $\gamma$ and lipopolysaccharide. Glia 29, 355-365. doi: 10.1002/(SICI)1098-1136(20000215)29:4<355::AIDGLIA6>3.0.CO;2-4 
Tai, Y. F., Pavese, N., Gerhard, A., Tabrizi, S. J., Barker, R. A., Brooks, D. J., et al. (2007). Microglial activation in presymptomatic Huntington's disease gene carriers. Brain 130, 1759-1766. doi: 10.1093/brain/awm044

Tambuyzer, B. R., Ponsaerts, P., and Nouwen, E. J. (2009). Microglia: gatekeepers of central nervous system immunology. J. Leukoc. Biol. 85, 352-370. doi: 10.1189/jlb.0608385

Tanaka, Y., Engelender, S., Igarashi, S., Rao, R. K., Wanner, T., Tanzi, R. E., et al. (2001). Inducible expression of mutant alpha-synuclein decreases proteasome activity and increases sensitivity to mitochondria-dependent apoptosis. Hum. Mol. Genet. 10, 919-926. doi: 10.1093/hmg/10.9.919

Tang, G., Perng, M. D., Wilk, S., Quinlan, R., and Goldman, J. E. (2010). Oligomers of Mutant Glial Fibrillary Acidic Protein (GFAP) inhibit the proteasome system in Alexander disease astrocytes, and the small heat shock protein aB-crystallin reverses the inhibition. J. Biol. Chem. 285, 10527-10537. doi: 10.1074/jbc.M109.067975

Tang, G., Xu, Z., and Goldman, J. E. (2006). Synergistic effects of the Sapk/Jnk and the proteasome pathway on glial fibrillary acidic protein (Gfap) accumulation in Alexander disease. J. Biol. Chem. 281, 38634-38643. doi: 10.1074/jbc.M604942200

Tao, J., Wu, H., Lin, Q., Wei, W., Lu, X., Cantle, J. P., et al. (2011). Deletion of astroglial dicer causes non-cell-autonomous neuronal dysfunction and degeneration. J. Neurosci. 31, 8306-8319. doi: 10.1523/JNEUROSCI.0567-11.2011

Tashiro, Y., Urushitani, M., Inoue, H., Koike, M., Uchiyama, Y., Komatsu, M., et al. (2012). Motor neuron-specific disruption of proteasomes, but not autophagy, replicates amyotrophic lateral sclerosis. J. Biol. Chem. 287, 42984-42994. doi: 10.1074/jbc.M112.417600

Thompson, L. M., Aiken, C. T., Kaltenbach, L. S., Agrawal, N., Illes, K., Khoshnan, A., et al. (2009). Ikk phosphorylates huntingtin and targets it for degradation by the proteasome and lysosome. J. Cell Biol. 187, 1083-1099. doi: $10.1083 /$ jcb. 200909067

Tofaris, G. K., Razzaq, A., Ghetti, B., Lilley, K. S., and Spillantini, M. G. (2003). Ubiquitination of a-Synuclein in Lewy bodies is a pathological event not associated with impairment of proteasome function. J. Biol. Chem. 278, 44405-44411. doi: 10.1074/jbc.M308041200

Tong, X., Ao, Y., Faas, G. C., Nwaobi, S. E., Xu, J., Haustein, M. D., et al. (2014). Astrocyte Kir4.1 ion channel deficits contribute to neuronal dysfunction in Huntington's disease model mice. Nat. Neurosci. 17, 694-703. doi 10.1038/nn.3691

Trotti, D., Rolfs, A., Danbolt, N. C., Brown, R. H. Jr., and Hediger, M. A. (1999). Sod1 mutants linked to amyotrophic lateral sclerosis selectively inactivate a glial glutamate transporter. Nat. Neurosci. 2, 427-433. doi: 10.1038/8091

Truant, R., Atwal, R. S., Desmond, C., Munsie, L., and Tran, T. (2008). Huntington's disease: revisiting the aggregation hypothesis in polyglutamine neurodegenerative diseases. FEBS J. 275, 4252-4262. doi: 10.1111/j.1742-4658.2008.06561.x

Tsai, Y. C., Fishman, P. S., Thakor, N. V., and Oyler, G. A. (2003). Parkin facilitates the elimination of expanded polyglutamine proteins and leads to preservation of proteasome function. J. Biol. Chem. 278, 22044-22055. doi: 10.1074/jbc.M212235200

Tseng, B. P., Green, K. N., Chan, J. L., Blurton-Jones, M., and Laferla, F. M. (2008). Abeta inhibits the proteasome and enhances amyloid and tau accumulation. Neurobiol. Aging 29, 1607-1618. doi: 10.1016/j.neurobiolaging.2007.04.014

Tydlacka, S., Wang, C., Wang, X., Li, S., and Li, X. (2008). Differential activities of the ubiquitin-proteasome system in neurons versus Glia may account for the preferential accumulation of misfolded proteins in neurons. J. Neurosci. 28, 13285-13295. doi: 10.1523/JNEUROSCI.4393-08.2008

Van Den Berge, S. A., Middeldorp, J., Zhang, C. E., Curtis, M. A., Leonard, B. W., Mastroeni, D., et al. (2010). Longterm quiescent cells in the aged human subventricular neurogenic system specifically express Gfap-delta. Aging Cell 9, 313-326. doi: 10.1111/j.1474-9726.2010.00556.x van Leeuwen, F. W., De Kleijn, D. P. V., Van Den Hurk, H. H., Neubauer, A., Sonnemans, M. A. F., Sluijs, J. A., et al. (1998). Frameshift mutants of $B$ amyloid precursor protein and Ubiquitin-B in Alzheimer's and Down patients. Science 279, 242-247. doi: 10.1126/science.279.5348.242

van Tijn, P., De Vrij, F. M. S., Schuurman, K. G., Dantuma, N. P., Fischer, D. F., Van Leeuwen, F. W., et al. (2007). Dose-dependent inhibition of proteasome activity by a mutant ubiquitin associated with neurodegenerative disease. J. Cell Sci. 120, 1615-1623. doi: 10.1242/jcs.03438

Vilchez, D., Boyer, L., Morantte, I., Lutz, M., Merkwirth, C., Joyce, D., et al. (2012). Increased proteasome activity in human embryonic stem cells is regulated by Psmd11. Nature 489, 304-308. doi: 10.1038/nature11468

Walker, A. K., Daniels, C. M., Goldman, J. E., Trojanowski, J. Q., Lee, V. M., and Messing, A. (2014). Astrocytic Tdp-43 pathology in Alexander disease. J. Neurosci. 34, 6448-6458. doi: 10.1523/JNEUROSCI.0248-14.2014

Walker, F. O. (2007). Huntington's disease. Lancet 369, 218-228. doi: 10.1016/S01406736(07)60111-1

Wang, L., Lin, F., Wang, J., Wu, J., Han, R., Zhu, L., et al. (2012). Expression of mutant N-terminal huntingtin fragment (htt552-100Q) in astrocytes suppresses the secretion of Bdnf. Brain Res. 1449, 69-82. doi: 10.1016/j.brainres.2012.01.077 Wyss-Coray, T., Loike, J. D., Brionne, T. C., Lu, E., Anankov, R., Yan, F., et al. (2003). Adult mouse astrocytes degrade amyloid-beta in vitro and in situ. Nat. Med. 9, 453-457. doi: 10.1038/nm838

Yamamoto, A., Friedlein, A., Imai, Y., Takahashi, R., Kahle, P. J., and Haass, C. (2005). Parkin phosphorylation and modulation of Its E3 ubiquitin ligase activity. J. Biol. Chem. 280, 3390-3399. doi: 10.1074/jbc. M407724200

Yan, L. J., Xiao, M., Chen, R., and Cai, Z. (2013). Metabolic dysfunction of astrocyte: an initiating factor in beta-amyloid pathology? Aging Neurodegener. 1, 7-14.

Zhang, D., Hu, X., Qian, L., O'callaghan, J. P., and Hong, J. S. (2010). Astrogliosis in CNS pathologies: is there a role for microglia? Mol. Neurobiol. 41, 232-241. doi: 10.1007/s12035-010-8098-4

Zhang, H., Tan, C. F., Mori, F., Tanji, K., Kakita, A., Takahashi, H., et al. (2008). Tdp-43-immunoreactive neuronal and glial inclusions in the neostriatum in amyotrophic lateral sclerosis with and without dementia. Acta Neuropathol. 115, 115-122. doi: 10.1007/s00401-007-0285-7

Zhao, X., and Yang, J. (2010). Amyloid-beta peptide is a substrate of the human 20 S proteasome. ACS Chem. Neurosci. 1, 655-660. doi: 10.1021/ cn100067e

Zheng, J., Dasgupta, A., and Bizzozero, O. A. (2012). Changes in 20S subunit composition are largely responsible for altered proteasomal activities in experimental autoimmune encephalomyelitis. J. Neurochem. 121, 486-494. doi: 10.1111/j.1471-4159.2012.07699.x

Conflict of Interest Statement: The authors declare that the research was conducted in the absence of any commercial or financial relationships that could be construed as a potential conflict of interest.

Received: 28 May 2014; accepted: 10 July 2014; published online: 08 August 2014. Citation: Jansen AHP, Reits EAJ and Hol EM (2014) The ubiquitin proteasome system in glia and its role in neurodegenerative diseases. Front. Mol. Neurosci. 7:73. doi: 10.3389/fnmol.2014.00073

This article was submitted to the journal Frontiers in Molecular Neuroscience. Copyright (C) 2014 Jansen, Reits and Hol. This is an open-access article distributed under the terms of the Creative Commons Attribution License (CC BY). The use, distribution or reproduction in other forums is permitted, provided the original author(s) or licensor are credited and that the original publication in this journal is cited, in accordance with accepted academic practice. No use, distribution or reproduction is permitted which does not comply with these terms. 